\title{
SEVILLA, CANARIAS Y EL ATLÁNTICO. LA CONTRIBUCIÓN HISTORIOGRÁFICA DE LA DRA. MANOLI RONQUILLO RUBIO (1960-2020)
}

\author{
SEVILLE, THE CANARY ISLANDS AND THE ATLANTIC. THE \\ HISTORIOGRAPHICAL CONTRIBUTION OF DR. MANOLI \\ RONQUILLO RUBIO (1960-2020)
}

\author{
Santiago de Luxán Meléndez* (iD), Ana Viña Brito ${ }^{* *}\left(\mathbb{D}\right.$, M. $^{a}$ de los Reyes Hernández \\ Socorro $^{* * *}$ (iD), Pablo Atoche Peña ${ }^{* * * *}$ (iD, Rosa Sierra del Molino ${ }^{* * * * *}$ (iD) \\ y M. ${ }^{a}$ Ángeles Ramírez Rodríguez ${ }^{* * * * * *}$ (iD
}

Fecha de recepción: 22 de febrero de 2021

Fecha de aceptación: 9 de mayo de 2021

Cómo citar este artículo/Citation: Santiago de Luxán Meléndez, Ana Viña Brito, M. ${ }^{a}$ de los Reyes Hernández Socorro, Pablo Atoche Peña, Rosa Sierra del Molino, M. a Ángeles Ramírez Rodríguez (2022). Sevilla, Canarias y el Atlántico. La contribución historiográfica de la Dra. Manoli Ronquillo Rubio (19602020). Anuario de Estudios Atlánticos; nº 68: 068-016.

http://anuariosatlanticos.casadecolon.com/index.php/aea/article/view/***

ISSN 2386-5571. https://doi.org/***

Resumen: Este trabajo aborda la trayectoria investigadora de la Dra. Ronquillo Rubio. Su obra se estructura en tres grandes líneas de investigación, dentro del marco general de la historia social de la época bajomedieval. Se trata de minorías sociales y profesionales: los procesos de integración en sociedades nuevas, el Atlántico y el azúcar y los orígenes de la Inquisición canaria en el marco de la historia atlántica.

Palabras clave: Ronquillo Rubio, Sevilla, Canarias, historia atlántica.

\begin{abstract}
This work addresses the research career of Dr. Ronquillo Rubio. His work is structured around three main lines of research, within the general framework of Social History of the late medieval period: social and professional minorities: integration processes in new societies, the Atlantic and sugar, and the origins of the Canarian Inquisition in the framework of Atlantic History.
\end{abstract}

Keywords: Ronquillo Rubio, Seville, Canary Islands, Atlantic History.

* Departamento de Ciencias Históricas. Grupo de investigación «G9. Historia, Economía y Sociedad» de la ULPGC. Universidad de Las Palmas de Gran Canaria. España. Correo electrónico: santiago.deluxan@ulpgc.es. Researcher ID: H-6938-2015.

** Departamento de Geografía e Historia. Grupo de investigación LexHis de la ULL. Universidad de La Laguna. Tenerife. España. Correo electrónico: anvina@ull.edu.es. Researcher ID: ABG-6881-2020.

*** Departamento de Arte, Ciudad y Territorio. Grupo de investigación «G9. Historia, Economía y Sociedad» de la ULPGC. Universidad de Las Palmas de Gran Canaria. España. Correo electrónico: mariadelosreyes.hernandez@ulpgc.es. Researcher ID: H-8293-2015.

**** Departamento de Ciencias Históricas. Grupo de investigación «G9. Historia, Economía y Sociedad» de la ULPGC. Universidad de Las Palmas de Gran Canaria. España. Correo electrónico: pablo.atoche@ulpgc.es. ID Autor Scopus: 56613356900, web personal: http://www.personales.ulpgc.es/patoche.dch/

***** Departamento de Ciencias Históricas. Grupo de investigación «G9. Historia, Economía y Sociedad» de la ULPGC. Universidad de Las Palmas de Gran Canaria. España. Correo electrónico: rosamaria.sierra@ulpgc.es. Researcher ID: ABH-4402-2020.

****** Departamento de Ciencias Históricas. Grupo de investigación «G9. Historia, Economía y Sociedad». Universidad de Las Palmas de Gran Canaria. España. Correo electrónico: angelesramirez57@gmail.com 


\section{INTRODUCCIÓN}

La historia del oficio de historiador es una forma particular de la historia de las humanidades. Se trata de una disciplina científica, es decir, un conjunto de escritos y actividades realizadas por una comunidad de profesores e investigadores para los que la historia es un ejercicio profesional que se desarrolla dentro de un marco institucional, principalmente constituido por la Universidad $^{1}$.

Sin necesidad de profundizar en la historia de la investigación histórica en Canarias, podemos señalar que durante los siglos XX-XXI tres ejes aglutinan su desarrollo. En primer lugar, las universidades. En segundo lugar, las publicaciones científicas de los historiadores que consagran su labor a realizar el discurso de la historia de Canarias. Finalmente, los foros de debate en los que se avanzan los resultados de la investigación y en los que tiene lugar el encuentro entre historiadores sénior y jóvenes investigadores.

La llegada de E. Serra Ràfols, del que se acaba de publicar su obra completa sobre Canarias ${ }^{2}$, a la Universidad de la Laguna ${ }^{3}$ será el precedente inmediato del quehacer histórico actual. El impulso definitivo se producirá durante los años finales de la década de los sesenta del siglo pasado con la creación de la sección de Historia en la Universidad de La Laguna (octubre de 1966). Más de dos décadas después, al final de los años ochenta del siglo XX, surgirá la Universidad de Las Palmas de Gran Canaria, que albergará en su seno un Departamento de Historia que propiciará, junto al de La Laguna, un incremento en la producción de tesis doctorales. Desde ese momento el interés por la historia de Canarias aumentará notablemente y su historia será tenida en cuenta en los foros y en las publicaciones internacionales.

Nos referíamos en segundo lugar a las publicaciones. En este caso debemos señalar en estos últimos cincuenta años una auténtica eclosión de publicaciones sobre nuestra Historia. Desde el momento en que se pusieron en marcha iniciativas como la edición actualizada de la Historia general de las islas Canarias de Millares Torres, desde Las Palmas ${ }^{4}$, o la de las Noticias de la historia de Canarias de Viera y Clavijo, desde Tenerife, las publicaciones han ido aumentando en calidad en todos los campos y la edición de monografías ha sido constante. En esta labor ha ocupado un papel fundamental el Cabildo de Gran Canaria, sin duda la editorial más importante del archipiélago. En el campo de las publicaciones periódicas, el Anuario de Estudios Atlánticos ${ }^{5}$, ahora en versión digital, desde mediados de los cincuenta es el referente principal de la producción científica. Junto al Anuario es imprescindible citar la Revista de Historia Canaria, la publicación científica más antigua de las islas, en la que se recoge igualmente el avance de la historia regional ${ }^{6}$.

El tercer eje al que aludíamos al principio lo constituyen los Coloquios de Historia CanarioAmericana $^{7}$, que con el patrocinio, igualmente, del Cabildo de Gran Canaria se han convertido en

\footnotetext{
1 CREYGHTON (2016), p. 15.

2 Obras Canarias de Elías Serra Ràfols (2019).
}

3 Sobre la historiografía canaria contemporánea cf. BETHENCOURT MASSIEU (1977), RÉGULO PÉREZ (1981), MARTÍN DE GUZMÁN (1990), LUXÁN (1993), MORALES LEZCANO (1996), GONZÁLEZ PÉREZ (2002), BAUCELS (2004), MACÍAS (2011), FARRUJIA (2010).

4 LUXÁN (1997).

5 «Publicado de manera ininterrumpida desde 1955, es una revista científica que abarca diversas materias, que se estructuran alrededor de sus tres temáticas principales: El Océano Atlántico como entidad histórica, La proyección exterior de las Islas Canarias y El Archipiélago Canario en sí mismo». http://anuariosatlanticos.casadecolon.com/index.php/aea/about

6 «La Revista de Historia Canaria, denominada así desde 1957, fue fundada en 1924 con el título de Revista de Historia. Constituye, bajo la tutela del profesorado de Historia e Historia del Arte de la ULL, un elemento fundamental a la hora de abordar y comprender la historiografía canaria desde principios del siglo XX. A través de ésta pueden observarse las tendencias, motivaciones e intereses que han estructurado los campos de estudios históricos en Canarias. Constituye el marco de referencia para el conocimiento y nuevas líneas de investigación que se llevan a cabo con relación a las islas desde la Prehistoria a la época actual». https://www.ull.es/servicios/publicaciones/publicacion/revista-de-historia-canaria/

7 «Los Coloquios de Historia Canario Americana, coordinados por el Dr. Francisco Morales Padrón, nacen en 1976 como una pequeña reunión de americanistas para tratar temas sobre las relaciones entre Canarias y América (...) Las reuniones, celebradas cada dos años, se han dividido en áreas temáticas, alrededor de las cuales se articulan las distintas ponencias y comunicaciones. Estas áreas centrales son actualmente: Arqueología, Arte, Geografía y organización territorial, Historia Económica, Historia Política e Institucional, Historiografía, Historia Social, Mujeres e Historia, y Multiculturalismo y Religiones en Canarias». http://www.casadecolon.com/coloquio-historia 
uno de los lugares de encuentro con más continuidad en el tiempo de nuestro país para debatir sobre cuestiones de historia. La nómina de historiadores que han pasado por la Casa de Colón, a través de sus sucesivas ediciones, así lo avala. En la actualidad el Coloquio se ha adaptado a las nuevas exigencias - la celebración del último coloquio en plena pandemia del COVID-19 así lo atestigua - y ha iniciado un proceso de modernización dirigido a mantenerse como centro en el que se debatan aspectos de interés en un mundo cada vez más globalizado y necesitado de reflexiones de larga duración.

Manuela Ronquillo Rubio estudió en la Universidad de Sevilla en los años en que eran profesores de aquella institución Francisco Morales Padrón, Miguel Ángel Ladero Quesada, Manuel González Jiménez e, incluso, Eduardo Aznar Vallejo, que luego será catedrático de Historia Medieval de la Universidad de La Laguna. En Sevilla se formará en Historia Medieval, especialidad en la que se incorporará a la Universidad de Las Palmas de Gran Canaria (19891990). Hay que resaltar que una de las fortalezas principales de la historiadora sevillana será su formación en Paleografía. Profesores e investigadores de esa universidad, además de los citados, serán Luis Núñez Contreras, Klaus Wagner, Pilar Ostos Salcedo, etc. De todos los nombrados interesa que retengamos el nombre de Eduardo Aznar Vallejo, catedrático de Historia Medieval de La Laguna, con el que Manoli conectará al llegar a Las Palmas y con el que realizará primero la tesina y más tarde su tesis doctoral. Junto a él, la también catedrática de Historia Medieval de la citada institución Ana Viña Brito, con la que colaborará estrechamente a lo largo de su trayectoria investigadora.

Desde la perspectiva de la historia atlántica, tal y como la definiera el profesor Elliot en un Coloquio de Historia Canario-Americana (octubre de 2000), y siguiendo la estela de los historiadores que inician en el siglo XX la historiografía canaria, es decir, Serra Ràfols, Peraza de Ayala, Rumeu de Armas, Morales Padrón y Bethencourt Massieu, entre otros, desde las universidades de La Laguna, Complutense de Madrid y Sevilla, la obra y la vida académica de Manuela Ronquillo no puede entenderse sino situándonos en dos focos interconectados: Sevilla y Canarias ${ }^{8}$. Con relación a Sevilla debemos señalar que será el sujeto y objeto de su principal investigación, consagrada a la integración de los vascos en la entonces Fortaleza y mercado, en expresión de Ramón Carande ${ }^{9}$, durante la Baja Edad Media. Su incorporación a la Universidad de Las Palmas de Gran Canaria en 1990 traerá consigo el estudio de la historia del archipiélago, integrándose en diferentes proyectos de investigación con los citados Aznar, Viña y con el catedrático de Prehistoria de la ULPGC Pablo Atoche Peña.

Escribe Elliott que el Atlántico es una construcción europea, «en esencia se trata de una invención de los siglos XV y XVI» ${ }^{10}$. «Un Atlántico único, vínculo de unión entre Europa, África y América [que] sugiere que hay motivo para un enfoque unificado de su historia», pero en el que podemos distinguir, a su vez, tres Atlánticos (hispano, portugués e inglés). En la etapa inmediatamente anterior al periodo de la unión ibérica (1580-1640), hubo una cierta convergencia - continúa Elliott- entre los Atlánticos español y portugués a una escala lo bastante importante como para permitirnos hablar de ellos como componentes de un solo Atlántico ibérico, en los aspectos defensivos y económicos $\mathrm{y}$, de modo especial, en el tráfico de esclavos ${ }^{11}$.

La historia de Canarias y la historia de Sevilla, en las que desarrolló su labor docente e investigadora la Dra. Ronquillo, forman parte de ese Atlántico que se conforma como ibérico. Las islas Canarias entrarán en colisión con Sevilla (Casa de Contratación), en determinados momentos de su devenir, terminada la conquista realenga, por el papel específico que tuvieron en la Carrera de Indias, que tan férreamente se trató de monopolizar desde Sevilla. Manoli se ocupó de los siglos anteriores al descubrimiento del Nuevo Mundo, etapa en la que se conforma el capital humano que intervendrá tanto en la conquista de las islas Afortunadas como en la colonización de las Indias. Desde esa perspectiva atlántica plena los intereses de la Dra. Ronquillo se refieren a la colonización de Canarias, al desarrollo de la potente economía del azúcar y a la implantación de las nuevas instituciones que dan cohesión a la naciente sociedad canaria, especialmente sobre

8 El Coloquio de Historia Canario-Americana de 2012 tuvo como tema monográfico «Sevilla, Canarias y América. El Atlántico como lugar de encuentro», en Homenaje a Francisco Morales Padrón.

9 CARANDE (1975).

10 ELLIOTT (2000), p. 14.

11 ELLIOTT (2012), pp. 25-26. 
los orígenes del tribunal inquisitorial. Un repaso a sus publicaciones y a los proyectos de investigación en que participó ratifican esta valoración del oficio de historiadora de la doctora sevillana.

Por lo que respecta a su participación en proyectos de investigación relacionados con la colonización del archipiélago canario, la doctora Ronquillo participó en diversos proyectos dirigidos por el profesor Atoche Peña desde el año 2000 hasta el momento de su fallecimiento: 1. «Modelos de poblamiento humano en islas: Incidencia romana en la colonización del Archipiélago Canario (PB98-0738)», financiado por la Comisión Interministerial de Ciencia y Tecnología (2000-2002). 2. «Efectos de la colonización insular. Transformaciones culturales y medioambientales en la Protohistoria de Lanzarote (PI042004/130)», financiado por la Dirección General de Universidades e Investigación del Gobierno de Canarias (2005-2008). 3. «Canarias: colonización humana protohistórica, bioadaptación insular y transformación medioambiental (HAR2009-08519)», financiado por el Ministerio de Ciencia e Innovación (2010-2012). 4. «Poblamiento, adaptación cultural y cambio medioambiental en la Protohistoria canaria: los casos de Lanzarote y Fuerteventura (HAR2013-40899-P)», financiado por el Ministerio de Economía y Competitividad (2014-2017). 5. «Colonización protohistórica del archipiélago canario: parámetros antropológicos, culturales y medioambientales (HAR2017-82792-P)», financiado por el Ministerio de Economía, Industria y Competitividad (2018-2021).

En conjunto se trata de proyectos diseñados para investigar los orígenes geográficos, étnicos y culturales de las comunidades que llevaron a cabo la colonización de las islas Canarias, cuestiones que han suscitado un gran interés entre eruditos e investigadores desde el mismo instante en el que los europeos bajomedievales entraron en contacto con las sociedades indígenas. Los conquistadores normando-castellanos que alcanzaron las islas en 1402 ya se cuestionaron quiénes eran y de dónde venían aquellos isleños que, aunque vivían en islas, no navegaban, tenían unas costumbres extrañas, hablaban diferentes lenguas y efectuaban unos ritos que poco tenían que ver con los que practicaban las religiones monoteístas presentes en la Europa del siglo XV. Fue precisamente en este ámbito de las fuentes escritas bajomedievales vinculadas a la colonización europea en donde la Dra. Ronquillo desarrolló su trabajo de investigación en los proyectos citados, poniendo en marcha tareas tendentes a la localización y documentación de las fuentes literarias existentes en relación con Canarias desde la etapa clásica grecolatina hasta la Baja Edad Media. Como resultado llevó a cabo un intenso trabajo de búsqueda bibliográfica en distintas bibliotecas y diferentes archivos nacionales e internacionales, que dieron como fruto la obtención de un conjunto de datos que permitieron una visión más nítida de la manera en que las islas fueron consideradas por las sucesivas culturas históricas (grecolatina, árabe, europea...) de su entorno más inmediato.

En Occidente, durante la Edad Media, el conocimiento acerca de las islas Canarias se circunscribió prácticamente a los estamentos sociales capaces de acceder a la información escrita, manteniéndose vinculado el conocimiento de la existencia del archipiélago a viejas y nuevas leyendas como las representadas por el Jardín de las Delicias de Isidoro de Sevilla (Etimologías, XIV) o la del monje irlandés San Brandán y su búsqueda de la isla de promisión que aparece y desaparece. No obstante, es en esa etapa cuando las islas comienzan a considerarse en Europa una realidad geográfica, debido a la actualización de la información disponible en relación con el océano producida a raíz de la puesta en marcha de expediciones exploratorias como la de los hermanos Vivaldi (circa 1291). En ese fenómeno de búsqueda se enmarcarán el establecimiento del genovés Lancelotto Malocello en la isla de Lanzarote durante la segunda década del siglo XIV (c. 1317) y la expedición portuguesa a las islas de 1341 al mando del también genovés Nicoloso da Recco. Sin embargo, la documentación que generaron las expediciones que visitaron Canarias no incorporan información acerca de la colonización insular o de cómo vieron los europeos de la época a los habitantes insulares. De hecho, habrá que esperar a la posterior presencia portuguesa y mallorquina, descrita por Gomes Eanes da Zurara, Alvise da Ca'da Mosto, Valentim Fernandes, Diogo Gomes de Sintra etc., para comenzar a contar con algunas noticias referidas al modo de vida y las costumbres de las comunidades insulares, aunque siguen sin apuntar la manera y las razones de su presencia en Canarias. El inicio de la conquista normando-castellana en 1402 permitió incrementar la información sobre las comunidades protohistóricas canarias y su cultura. Las primeras indicaciones acerca de su posible origen aparecen en las crónicas francesas de la 
conquista (Le Canarien $)^{12}$, texto en el que se documenta la denominada Leyenda de las lenguas cortadas, primer intento conocido de explicar cómo se produjo la colonización humana de alguna isla del archipiélago. Esa leyenda ha conseguido perpetuarse en algunos círculos académicos como explicación de las causas y la forma en que se produjo el poblamiento de Canarias. Otras crónicas elaboradas en el siglo XV, como la referida a la conquista de Gran Canaria, atribuida a Alonso Jáimez de Sotomayor, no se ocupan del origen de la población canaria. Ocurre lo mismo en los textos de Francisco López de Ulloa, Antonio Sedeño, Pedro Gómez Escudero, Alonso de Palencia o Diego de Valera. Por el contrario, Andrés Bernáldez, en su Memoria del reinado de los Reyes Católicos, asegura que los ancianos canarios consideraban que los primeros habitantes habían sido trasladados al archipiélago.

Además de su trabajo documental con las fuentes escritas, la actividad desarrollada en el seno de los citados proyectos hizo que la Dra. Ronquillo colaborara en las intervenciones arqueológicas programadas en la isla de Lanzarote en los importantes yacimientos de El Bebedero y Buenavista, ambos en el municipio de Teguise. Igualmente, la relación que estableció con la historia de Lanzarote le permitió, en unión de la Dra. Viña Brito, acometer la elaboración del tomo 2 de la Historia de Teguise, trabajo inédito que se encuentra en proceso de finalización y que corresponde a una obra general, iniciativa de la directora del Archivo Histórico de Teguise, M. ${ }^{a}$ Dolores Rodríguez Armas, que abrió al equipo de investigación dirigido por el Dr. P. Atoche, y en el que se integró la Dra. Ronquillo, la posibilidad de poner en marcha un proyecto dirigido a profundizar en el conocimiento que se poseía sobre la historia de Teguise. Dicho proyecto debía abarcar cronológicamente desde los orígenes protohistóricos de la colonización humana de la isla hasta el cambio de la capitalidad insular a mediados del siglo XIX, centrando sus trabajos de investigación en la obtención de información primaria, muy escasa para algunas de las etapas en estudio, dispersa y, en el caso de la etapa protohistórica, aún por descubrir al encontrarse enterrada en yacimientos que había que localizar, excavar y analizar de manera adecuada. El convenio de colaboración entre el Ayuntamiento de Teguise, la Universidad de Las Palmas de Gran Canaria y la Fundación Universitaria de Las Palmas estableció un programa de trabajo que debía dar como resultado la redacción de tres volúmenes dedicados, el primero, a la etapa protohistórica, el segundo, a la Baja Edad Media y el inicio de la Edad Moderna, y el tercero, al resto de la Edad Moderna y la primera mitad de la Edad Contemporánea, atendiéndose de esa manera a las peculiaridades que tuvo el desarrollo histórico de Teguise.

La colaboración de la profesora Ronquillo Rubio se evidencia, asimismo, en su participación en varios proyectos de investigación dirigidos por el Dr. Aznar Vallejo como «Castilla y el mar en la Baja Edad Media», formando parte del Grupo de Investigación sobre «Historia Marítima. Castilla y el mar», de la Universidad de La Laguna, y con la Dra. Sierra del Molino en proyectos sobre la mujer, como señalaremos en el epígrafe correspondiente.

También colaboró con el grupo interdisciplinar LexHis de la ULL y en los momentos iniciales del proyecto CORDICan, que desafortunadamente no ha podido ver finalizado, aportando documentos sobre la temática azucarera denunciados ante el tribunal inquisitorial.

Además de su participación en los proyectos que acabamos de enumerar, el legado científico de Manoli puede denominarse sin más matices como una importante contribución a la historia social, en el tiempo bajomedieval.

Para poder entender mejor sus aportaciones, que abarcan desde los comienzos de la década de los 90 hasta el final del segundo decenio del siglo XXI, hemos estructurado sus trabajos en seis líneas con vasos comunicantes porque todas sus indagaciones son, en el lenguaje actual, transversales. Desde esa consideración podemos encontrar en sus artículos, libros, capítulos de libros y comunicaciones a congresos, investigaciones que podemos etiquetar como contribuciones al estudio de minorías sociales y profesionales, a la historia social y económica del azúcar en Canarias, a los orígenes de la Inquisición, a la edición de fuentes y documentos historiográficos, a la mujer y, finalmente, a la religión y espiritualidad (mentalidades).

12 AZNAR y otros (2006). 


\section{MINORÍAS SOCIALES Y PROFESIONALES: LOS PROCESOS DE INTEGRACIÓN EN SOCIEDADES NUEVAS}

En este apartado incluimos investigaciones referidas tanto a Sevilla como a Canarias. Desde nuestro punto de vista constituyen la parte más importante de su investigación y podemos considerar que en los tiempos presentes son de total actualidad.

Los vascos en Sevilla y su tierra durante los siglos XIII, XIV y XV: fundamentos de su éxito y permanencia $^{13}$ es una contribución fundamental, como hemos señalado, al estudio de la formación del capital humano de la metrópoli sevillana, antes de convertirse en el centro del mundo, en un mundo abreviado, como se escribirá en el siglo XVIII ${ }^{14}$.

Los vascos en Sevilla y su tierra ${ }^{15}$ constituye una importante aportación al conocimiento de la sociedad que, desde Sevilla, iniciará en el siglo XV la expansión atlántica. Es un trabajo exhaustivo en cuanto a las fuentes utilizadas y su tratamiento, tras una búsqueda sin tregua en los principales archivos españoles. Se trata de una indagación que nos aclara las características, causas y enraizamiento en la Baja Andalucía de la población procedente del norte de la Península. La elección de un marco cronológico de tres siglos nos permite tener una visión estructural y, a la vez, dinámica de los problemas que tuvo esta minoría. Estamos, finalmente, ante una inmigración que alcanzó un éxito notable en su adaptación al nuevo medio, convirtiéndose en uno de los elementos que dinamizará a la sociedad andaluza en los momentos clave de la aventura atlántica.

Esta monografía aborda uno de los fenómenos de desplazamientos menos estudiados hasta ese momento, el de la presencia e instalación de oriundos de Vizcaya, Guipúzcoa y Álava en Sevilla y su tierra durante los siglos XIII, XIV y XV. En el momento de su publicación, aunque sabíamos de la presencia vasca en Andalucía, no se había abordado un estudio en profundidad sobre sus orígenes. En los diversos trabajos sobre comercio bajomedieval castellano se constataban las actividades que permitieron en parte la movilidad hacia el sur de la Península. Aun percibiéndose que el número debía ser mayor al que se apuntaba, no se había intentado recoger ni cuantificar de forma sistemática. Gracias a este estudio pudo avanzarse en el nivel de conocimientos que hasta el momento teníamos, ya que no se limita a una relación de las actividades de los vascos como mercaderes y transportistas en la ciudad hispalense, sino que ofrece múltiples perfiles de lo que fue su asentamiento en la región. Estos dos sectores, además, no fueron los únicos renglones productivos en que los vascos desplegaron su actividad en Andalucía. La paciente investigación de la Dra. Ronquillo ha sacado a la luz un buen elenco de artesanos, desde la década de 1430 en Sevilla, o desde 1460 en Córdoba, junto con los que ejercieron cargos y oficios públicos en diferentes ciudades andaluzas.

Partiendo de una amplia recopilación de fuentes, no solo en los archivos nacionales, sino también en las ediciones de cronistas y colecciones documentales, se ha elaborado un amplio trabajo de la presencia de los vascos en Andalucía, y sobre todo en Sevilla y su tierra, insertándolo en una línea que tiende a analizar tanto a los protagonistas del crecimiento económico andaluz (no en vano los vascos se asientan por igual en la ciudad como en la tierra) como a los impulsores de la navegación atlántica del reino de Castilla durante el siglo XV.

El análisis de fuentes primarias para la realización de esta investigación ha sido excepcional y exhaustivo. De este modo, se ha procedido a la revisión de todos los padrones, alardes, censos fiscales, etc., de los vecinos de Sevilla, desde fines del XIV hasta 1512. Igualmente, se han estudiado todos los protocolos notariales que conserva la ciudad desde 1448 a 1503, junto a algunos de Córdoba. Los grandes archivos nacionales están también presentes en el corpus documental analizado por Ronquillo Rubio: Archivo General de Simancas, Chancillería de Valladolid, Archivo General de Indias, Archivo Histórico Nacional y Museo Naval. De la misma manera grandes colecciones documentales, como las «Fuentes Documentales Medievales del País Vasco», fueron tenidas en cuenta.

Además de perfilarse las causas y factores que actuaron en el proceso migratorio, se cuantifica el fenómeno, demostrando a la vista de la documentación cuántos vascos y en qué fechas estaban en Sevilla y su tierra, y si se trató de oleadas o de líneas individuales de acción. Por tanto, se

13 RONQUILLO (2004).

14 CANSINO Y CASAFONDA (1751).

15 LUXÁN (2004). 
analizan los ritmos o períodos cronológicos de asentamiento, las características de los que permanecen, las relaciones familiares que tejieron y los espacios políticos y económicos que ocuparon. Asimismo, se valora la incidencia del grupo en el contexto socioeconómico andaluz y sevillano, ofreciendo la posibilidad de observar un nuevo modelo de comportamiento en las relaciones sociales de producción tanto intergrupales (entre vascos y la sociedad sevillana) como dentro del propio grupo vasco.

Una de las conclusiones más interesantes del análisis realizado en esta investigación es la de la falta de homogeneidad entre los vascos que se establecieron en Sevilla entre mediados del siglo XIII y finales del XV. La respuesta está en la casuística de sus desplazamientos, que variaron en el transcurso del tiempo: conquista, repoblación, puesta en explotación del territorio andaluz, obtención de mercedes y cargos por parte de los reyes, causas socioeconómicas en sus lugares de origen, desarrollo comercial de las villas vascas, etc. Como tampoco existió igualdad en las proporciones de vizcaínos, guipuzcoanos o alaveses que se desplazaron hasta Andalucía. Pese a que los alaveses priman en la primera etapa (la de conquista y repartimientos de tierras), serán definitivamente los vizcaínos y los guipuzcoanos los que ocupen el primer lugar durante todo el siglo XV. Igualmente, en cuanto a sus categorías socioeconómicas y jurídicas, también existen variaciones a lo largo de esos tres siglos según provengan de líneas menores de los grandes linajes vascos, fuesen simples hidalgos, o habitantes de las villas vascas más desarrolladas en busca de mejores oportunidades, y de mantener y elevar su nivel económico. Es de destacar, asimismo, la gran capacidad de adaptación del grupo vasco a la realidad socioeconómica sevillana en la que se integra de modo rápido en todas las ocasiones, aunque persistan ciertos rasgos diferenciadores. Se percibe sutilmente el mantenimiento de una solidaridad familiar concreta, como también el de la utilización de toponímicos de raigambre vasca incluso en familias asentadas de antiguo. Por último, el éxito alcanzado por los diferentes grupos socio-jurídicos vascos en el sur es visible tanto en la diversidad de funciones que desempeñan como en las relaciones que entablan con los niveles oficiales sevillanos (del poder, mercantiles, eclesiásticos), como en las vías de acceso empleadas para ocupar parte de ese poder o del espacio económico local, en particular los que se asientan en el siglo XV y llegan a alcanzar puestos de mayordomos del Cabildo, jurados y regidores. Todo ello conforma las bases sobre las que se sustenta la importancia que los vascos tendrán en Sevilla durante la Edad Moderna.

Hemos destacado de esta publicación sobre la Baja Edad Media española y sobre el mundo atlántico cuestiones fundamentales que han significado una presencia notable en la historiografía española que, aún hoy, la convierten en una referencia fundamental, como confirma que el tema tratado por Manoli haya tenido su continuación en el análisis de la formación de redes sociales y familiares, que ha ocupado últimamente a los medievalistas y a los historiadores en general.

La más reciente publicación de la historiadora sevillana «Mercaderes vascos en la Baja Andalucía y Canarias (fines del siglo XV-1520)» apareció en 2019 en un libro titulado Mercaderes y redes mercantiles en la Península Ibérica. Siglos XV-XVIII, y nos atrevemos a escribir que puede ser considerado el resumen del legado sobre esta línea de investigación que abrió su tesis doctoral. En este libro, en el que el estudio de Ronquillo demuestra lo difuso de las líneas que separan la Baja Edad Media del mundo moderno, leemos en su resumen:

Se ha tratado de reconstruir a través de varios estudios de caso la dimensión plural de las diferentes esferas del mundo mercantil que se desarrollaban en la pujante Península Ibérica de la Edad Moderna. Su creación responde a un esfuerzo por aproximar resultados de investigación y líneas historiográficas como forma de promocionar una colaboración académica internacional más estrecha entre modernistas de Francia, Portugal y España. Dicha colaboración se nos antoja como un elemento necesario a la hora de obtener resultados de trabajo de mayor calado, como una herramienta útil para acelerar la puesta en común de resultados científicos de cara a orientar las líneas de trabajo e investigación hacia objetivos más amplios.

Otra secuela de la investigación seminal de Manoli Ronquillo fue presentada en los Encuentros Internacionales del Medievo de Nájera, editados por el Instituto de Estudios Riojanos en 2015, bajo el título de aquella convocatoria, Diplomacia y comercio en la Europa atlántica medieval. Efectivamente, hoy no nos extraña que se valore con perspectiva histórica, en el período de la Guerra Fría posterior a la Segunda Guerra Mundial, la importancia de la diplomacia corporativa, 
la diplomacia empresarial, que va por delante o al margen de las relaciones políticas ${ }^{16}$. O que, en las centurias anteriores del capitalismo comercial (mercantilismo), los historiadores se refieran como un hecho constatado al trato comercial con el enemigo ( «comerciando con el enemigo» ${ }^{17}$ ). Volviendo a los Encuentros, los temas allí tratados concuerdan plenamente con la tesis de Manoli (las gentes del mar y las sociedades portuarias). Estamos ante un indicador claro de la internacionalización de los estudios bajomedievales en los que se inserta la obra de la historiadora sevillana ${ }^{18}$. La participación de Manoli se ciñó en estas Jornadas a definir a la colonia mercantil vasca de Híspalis.

Igualmente, surge a rebufo de su tesis y del problema de la integración de las minorías foráneas en las ciudades y sociedades medievales la contribución al homenaje al profesor García de Cortázar, del que se confiesa discípula (Mundos medievales: espacios, sociedades y poder: homenaje al profesor José Ángel García de Cortázar y Ruiz de Aguirre) en 2012. En este caso, Manoli hace cruzar el mar a los vascos y los emplaza en la conquista realenga de Canarias (14761500). Si en los años centrales del siglo XV los hombres del norte de España se asentaron en las islas de señorío, especialmente en la de Lanzarote, mostraron, sin embargo, un mayor interés en los negocios propiciados por la conquista realenga. De intervenir inicialmente en las armadas de la conquista y en la actividad de corso, su actividad se modifica y acaban siendo comerciantes y transportistas. El asentamiento de vascos en Gran Canaria, Tenerife y La Palma nos presenta a un conjunto muy variado de individuos. Quienes llegaron con la conquista recibieron su parte de tierra y agua (datas y repartimientos), participando plenamente en la colonización. Los que lo hicieron más tarde pasaron a formar parte de la población mercantil de las ciudades portuarias de las islas y, por lo tanto, a integrarse en la élite. El tema de los vascos fue apuntado en su día por Zuaznavar en el siglo XIX y en la época actual se han referido a él Eduardo Aznar ${ }^{19}$, Manuel Lobo $^{20}$, la propia Manoli ${ }^{21}$ y Murillo ${ }^{22}$.

Las islas señoriales también fueron lugares de recepción de población vasca. Manoli redactó sobre este aspecto una comunicación («Los vascos en Canarias durante la época señorial»), al XV Coloquio de Historia Canario-Americana (2004), que atestigua, aún más, la conexión SevillaCanarias y la temática de su investigación principal, pero indagando, esta vez, sobre fuentes secundarias canarias. Martín de Avendaño en el siglo XIV y Diego de Herrera en el XV sirven como hilos conductores para intentar sistematizar la llegada de pobladores oriundos del País Vasco a las islas. Desde mediados del XIV hasta principios del XV fueron constantes las visitas de castellanos para hacer aguada, tomar provisiones, descansar o coger sangre de drago, y en ellas pudieron incluirse algunos vascos. La primera arribada histórica de un vasco a las islas podría situarse en el momento de la guerra luso-castellana. La figura de Martín Ruiz de Avendaño fue sacada a la luz por Abreu Galindo, para quien dicho vizcaíno,

que corría todas las costas de Vizcaya, Galicia e Inglaterra en tiempos de las luchas de Castilla contra Portugal y el Duque de Lancaster, fue nombrado capitán de una armada para vigilancia del océano, llevándolo un fuerte temporal a la costa lanzaroteña donde lo recibieron los aborígenes y lo aposentaron.

Según Abreu o Torriani, los vascos pudieron encuadrarse en las expediciones depredatorias a Berbería entre 1385-1393. Entrado el siglo XV, la ascendencia vasca de Diego de Herrera escribe Manoli- debió incidir en la llegada de un grupo de pobladores de este origen. Eran individuos de baja categoría nobiliaria que acudieron con el cebo de poseer tierras, y junto a ellos algún «marino» residente en Sevilla. Puede concluirse que, entre la llegada de Diego de Herrera y la conquista realenga, un número creciente de vascos se asentaron en las islas, en particular en Lanzarote.

16 YANISHEV (2019).

17 GARCÍA FERNÁNDEZ (2005 y 2006).

18 Una reseña de estas Jornadas en GONZÁLEZ ZALACAÍN (2016), pp. 869-873.

19 AZNAR VALLEJO $(1982,1986)$

20 LOBO CABRERA (1993) pp. 553-565 y (2004), pp. 807-814.

21 RONQUILLO RUBIO (2004), pp. 2058-2072.

22 MURILLO (2014-2015). 
Este apartado se cierra con tres trabajos consagrados al estudio de las minorías. El primero es un estudio de la población extranjera de Sevilla en torno a 1640, realizado en colaboración con Santiago de Luxán y presentado al II Congreso de Historia de Andalucía (Córdoba 1991). A través de los padrones, mandados a hacer por parroquias por el conde-duque de Olivares, parece que, tratando de identificar a los lusitanos, entonces en rebelión, el recuento de población nos muestra que los portugueses son mayoría y nos sorprende la consideración de los vizcaínos como extranjeros. Fue un trabajo, también anterior a la publicación de la tesis, el dedicado a uno de los vascos que acabaría teniendo un papel relevante en el Cabildo sevillano, «La promoción de una familia de artesanos vascos en el siglo XV. Nicolás Martínez de Durango, Mercader, Jurado y Mayordomo del Cabildo sevillano»:

La Sevilla bajomedieval —escribe Manoli en su estudio dedicado esta vez a la minoría de ascendencia gallega - fue una ciudad bastante receptiva respecto a la presencia de una buena cantidad y variedad de recién llegados con orígenes y calificaciones profesionales diversas. En particular los extranjeros, que ayudaron tanto a potenciar su desarrollo mercantil, han sido objeto de investigación en muchas ocasiones, pero no fueron los únicos implicados en dicho desarrollo. Ciertos grupos castellanos, concretamente los vascos que han sido analizados desde el siglo XIII al $\mathrm{XV}$, y los burgaleses del último tercio del siglo $\mathrm{XV}^{23}$, aparecen igualmente en la base de la vitalidad comercial de esta ciudad. Puesto que es imposible hacerse una idea aproximada del papel que cualquier grupo foráneo puede desplegar en los ámbitos urbanos de significativa actividad mercantil, finalmente habrá que analizarlos todos. Por tal razón, y por el sustancial número que aparece en las fuentes, hemos comenzado a estudiar a los gallegos residentes tanto en la ciudad como en su entorno rural a lo largo del siglo $\mathrm{XV}^{24}$.

\section{EL ATLÁNTICO Y EL AZÚCAR}

El trabajo de Manoli en torno al azúcar se encuadró, en primer lugar, dentro del proyecto $<<E 1$ azúcar y la cultura en las islas atlánticas. Valoración y gestión sostenible de los recursos culturales para el desarrollo turístico y territorial de Canarias y Madeira como destinos de calidad $>>$, Iniciativa comunitaria, INTERREG III, B 2000-2006 MAC 4.5/C14, en el que confluimos las universidades de La Laguna, Las Palmas de Gran Canaria y el Centro de Estudos de Historia do Atlántico de Madeira, hoy Centro de Estudos de História do Atlântico Alberto Vieira ${ }^{25}$.

Los primeros resultados del proyecto Atlántica, ${ }^{26}$ articulados en forma de comunicaciones o libros, se presentaron en el XVI Coloquio de Historia Canario-Americana (Las Palmas, 4-8 de octubre de 2004) y en el III Seminario Internacional sobre a História do Açúcar (Funchal, 25-29 de octubre de 2004). El proyecto Atlántica, en el que se incluyen los estudios de Manoli en colaboración con Ana Viña, estaba estructurado en tres apartados fundamentales: Historia, dividido a su vez en dos bloques (Primer ciclo del azúcar — especialmente siglos XV-XVI- y Segundo ciclo, 1852-1936); Arte y Patrimonio, en el que se incluyeron el arte flamenco, la arquitectura del azúcar y la iconografía de los hombres del azúcar; y Geobotánica, en el que se trató de medir la influencia de esta actividad en la vegetación de las islas. Quizá una de las aportaciones más interesantes de este proyecto fue la metodología interdisciplinar del mismo, la serie de miradas transversales, y desde espacios geográficos cercanos, que se realizaron sobre el azúcar.

En la sección del Coloquio de Las Palmas consagrada al azúcar (coordinada por Santiago de Luxán y Ana Viña), dentro de la línea de investigación del proyecto Atlántica, que se propuso poner en valor la historia del azúcar como recurso patrimonial y cultural, se presentaron diversas comunicaciones por parte de los investigadores de las universidades de La Laguna y de Las

23 PALENZUELA (2003).

24 RONQUILLO (2007), pp. 151-186.

25 O Centro de Estudos de História do Atlântico, criado pelo decreto legislativo regional n. ${ }^{\circ}$ 20/85, de 17 de Setembro, no âmbito da Secretaria Regional do Turismo e Cultura, é uma instituição de investigação científica que tem por objectivo principal coordenar a investigação e promover a divulgação da história das Ilhas Atlânticas. https://ceha.madeira.gov.pt/.

26 Cf. LUXÁN (2004). 
Palmas, se realizó un análisis historiográfico del desarrollo de la caña y la producción de azúcar entre los siglos XV-XVII a cargo de Ana Viña y Manoli Ronquillo, un estudio del marco institucional y su influencia en el desarrollo del complejo agroindustrial del azúcar canario, entre la declaración de los Puertos Francos de 1852 y los comienzos de la Guerra Civil española de 1936, que ofrecieron Santiago de Luxán y Óscar Bergasa, un análisis de la iconografía de los hombres del azúcar en el mismo período que la anterior comunicación (María de los Reyes Hernández Socorro y Santiago de Luxán) y un estudio de geobotánica referido a los siglos XVXVI (Agustín Naranjo y Octavio Rodríguez). Entre las comunicaciones madeirenses, debemos citar el análisis del arte flamenco en Madeira (Rui Carita) y un estudio referido a la tecnología del azúcar (Alberto Vieira).

El azúcar en las islas —escriben Viña y Ronquillo, que es el único estudio al que vamos a referirnos ahora- ha sido un tema recurrente en la historiografia canaria. Realizar un balance de la producción histórica se presentaba, sin embargo, como una tarea ardua por varias razones: enorme dispersión de los trabajos publicados, escasa presencia de estos en los estados de la cuestión que hasta la fecha se habían realizado sobre la historiografía canaria (de modo específico, los consagrados al comercio), insularidad de los estudios realizados, con la consiguiente dificultad para poder ofrecer una visión general, etc.

El balance historiográfico pretende no ser una lista bibliográfica por autores, sino un análisis sistemático, insular y global, que no deje fuera la relación con otros territorios, dentro de un marco cronológico que va desde la incorporación de las islas a la corona de Castilla hasta la decadencia del cultivo, a fines del siglo XVI. En cuatro grandes áreas temáticas quedó estructurado el estado de la cuestión: fuentes y legislación, comercio, el elemento humano y cultura y mentalidades.

En cuatro grandes etapas, igualmente, se estructuró la producción historiográfica referente al azúcar: $1 .{ }^{a}$ Las Crónicas de la Conquista; $2 .{ }^{a}$ El siglo XVI: Nichols, Torriani y Frutuoso; 3. ${ }^{a}$ Los siglos XVII-XVIII: Núñez de la Peña, Marín y Cubas, Viera y Clavijo — que es presentado como el historiador más analítico-y Agustín del Castillo; 4. ${ }^{a}$ 1850-2004: en la que se destacan los nombres propios de Millares Torres, Chil y Naranjo y los historiadores que empiezan a trabajar en la década de los setenta (Aznar, Lobo, Macías, Viña Brito, etc.).

Queremos dejar constancia, finalmente, de tres cuestiones que a nuestro entender fueron repetidas en la presentación del Coloquio: en primer lugar, la preocupación y el oficio que deben mostrar los historiadores de las islas para citar sus fuentes de información, evitándose, de esta manera, repeticiones y tópicos infundados. En segundo lugar, el cambio cualitativo que en el estudio del azúcar se produce a partir de la década de los setenta del siglo XX. Finalmente, con relación a los resultados obtenidos, puede decirse que se ha hecho un enorme esfuerzo en la publicación de fuentes (hay que seguir en la línea de reeditar y publicar nuevas fuentes, entre las que hay que incluir los libros de viajes); el marco institucional parece ser que es el mejor conocido; en los temas relacionados con el comercio, nos falta quizá una visión de conjunto; el elemento humano también ha sido bien estudiado y, por último, todavía se puede caminar - el terreno del arte flamenco ha sido bien investigado - en el campo de las mentalidades.

De nuevo, Viña y Ronquillo, dentro de este proyecto, presentaron un estudio en el marco del III Seminario de Historia do Açucar de Funchal, celebrado ese mismo año, seminario al que se incorporó el historiador del arte de La Laguna Jesús Pérez Morera. El azúcar fue un producto sometido a una reglamentación estricta con una influencia decisiva en la conformación social y económica del archipiélago canario. Este es, a nuestro juicio, el principal mensaje que se ofreció en Madeira.

El azúcar en Canarias ha sido uno de los temas más recurrentes de la historiografía tanto local como nacional e internacional, con aportes que podrían resumirse, sin ser los únicos, en dos planteamientos diferenciados. El primero de ellos abarcaría las publicaciones realizadas aproximadamente hasta la década de los años setenta del siglo XX. Referirse a la economía de las islas era en gran medida señalar los distintos ciclos productivos a lo largo de su historia, anotando que el principal en el siglo XVI era el «monocultivo del azúcar». Asimismo, se indicaba que el modelo azucarero de Madeira y Canarias era un retrato en miniatura de lo que sucedió posteriormente al otro lado del Atlántico. El segundo aporte historiográfico parte de los estudios realizados a partir de esa fecha, en los que se situaba al azúcar como el principal producto de 
exportación desde un punto de vista cualitativo, pero también como «eje vertebrador de la sociedad canaria en el siglo XVI ${ }^{27}$.

En el trayecto que siguió la caña de azúcar desde sus remotos orígenes en Guinea-Papúa hasta llegar al Nuevo Mundo, las islas atlánticas constituyeron uno de los jalones más importantes. Incluso, consideramos que su papel en Canarias fue determinante en el devenir histórico del archipiélago, porque a través de este pueden explicarse los contornos de una estructura social concentración de tierras y aguas, esclavitud- y económica específica. Dentro de esta última se entienden los cambios técnicos y un poblamiento característico que materializa la llamada civilización del azúcar en el mundo atlántico que ha modelado gran parte del paisaje insular, sin olvidar la importancia del sector comercial, pues ninguna cultura ni producto final contaron con una vigilancia y reglamentación tan estricta como el azúcar.

En efecto, la implantación del azúcar en el archipiélago es coetánea al proceso de colonización de las islas, llevándose a cabo una política de atracción de pobladores y fomento de la mano de obra (fue muy importante el aporte de los archipiélagos vecinos), pues en el cultivo de la caña de azúcar la explotación directa es la norma habitual con la colaboración de los cañaveros y la legislación relativa a este producto alcanza niveles extremos.

La excesiva reglamentación se orienta, sobre todo, a la comercialización del producto, aunque también la normativa afecta al proceso de producción. En la legislación relativa al azúcar en sus diferentes fases encontramos un fuerte contraste entre lo acaecido, por ejemplo, en Madeira, donde la legislación es más específica para las labores de zafra e ingenio, posiblemente porque el municipio portugués goza en el siglo XVI de una amplia autonomía, así como de una elevada participación de las gentes en el gobierno y lo sucedido en Canarias, donde destaca la fuerte intervención de la Corona en las islas de realengo y de los señores en las de señorío. Ello es básico para entender el sentido de la legislación que regula el azúcar en este ámbito, en particular en lo referente a los beneficios que esperan tanto la Corona o los señores como, evidentemente, los dueños de ingenio, que, en muchos casos, formaban parte de la oligarquía local.

Por lo que respecta al proceso concreto de la comercialización del azúcar de Canarias, no suscitó la misma intervención y atención de la Corona, pues el trato fue dejado a la iniciativa de mercaderes nacionales o extranjeros, principalmente genoveses y flamencos, y es aquí donde el control normativo local alcanza su punto álgido.

Un factor que influyó decisivamente en la importancia del azúcar para las islas, aparte de los excelentes mercados europeos cuya demanda aumentó considerablemente, fueron los especiales beneficios concedidos a las islas Canarias desde la Administración central, que sirvieron, además, de incentivo para la fijación de colonos; prácticamente quedaron exentas de pechos y servicios reales $^{28} \mathrm{y}$, sobre todo, el hecho de que las franquicias canarias, a diferencia de lo que por ejemplo sucedía en Granada, llegaron a ser casi perpetuas a cambio de un porcentaje de almojarifazgo, que fueron siempre muy bajos respecto a las ordenanzas vigentes en otras partes del reino.

Estas ventajas, en cuanto a la participación de las islas en la Hacienda regia, también afectaron positivamente a las rentas eclesiásticas, como se observa, por ejemplo, en la percepción del diezmo. La mitad de la producción de los señores de ingenio quedó exenta, debido a los grandes gastos que requería su elaboración. Por esta causa el diezmo constituía una arroba de azúcar blanco de cada 20, quedando libres las escumas y las rescumas. Este convenio favorecía a los dueños de ingenio y a los receptores del diezmo, que preferían llevar la mencionada cantidad de azúcar que la décima parte de las cañas. Frente a esta postura estaban los agricultores, quienes defendían que ellos solo estaban obligados a pagar «uno de cada diez haces de caña, una vez limpias y desburgadas». Este enfrentamiento se tradujo en un pleito, confiado a Ciprián Gentil, colector apostólico y juez árbitro, que en sentencia pronunciada en 1487 confirmó la práctica tradicional y la pérdida de las cañas que el obispo y Cabildo no habían querido aceptar. Este sistema se mantuvo invariable hasta el año 1515 , cuando el nuevo obispo trató de percibir el diezmo sobre la totalidad del azúcar producido, intento que hubo de abandonar en 1519 ante la amenaza de volver a diezmar en los cañaverales.

27 VIÑA BRITO (2014), p. 15.

28 MIRANDA (2017). 
Esta política de protección y control estuvo orientada, en Canarias, a garantizar la exportación en las mejores condiciones posibles, de ahí que se regule incluso la tipología de los envases en cajas de madera de tilo, se fije el precio del azúcar blanco para evitar su depreciación, etc. Por otra parte, el alto rendimiento de este cultivo provocó que Madeira y Canarias se convirtiesen en las plataformas para el arranque de los caminos a nuevas tierras ${ }^{29}$, pero, sobre todo, que se afirmasen como áreas de convergencia de muchos intereses atlánticos y mediterráneos en expansión. Así pues, en Canarias se asienta un comercio intensivo de trasbordo a otros lugares de Castilla, compañía de Cádiz, a Indias como proveedores de confituras y conservas, a Berbería en mieles y remieles y a Flandes, como destino principal del azúcar canario ${ }^{30}$.

A pesar de que, como ya señalamos, en el caso canario la mayor parte de la legislación local estuvo orientada a la regulación y estricto control y protección de la exportación, también encontramos disposiciones relativas a las labores de plantación, zafra y, por supuesto, al proceso de transformación, pues de ello dependía la calidad en la exportación del producto final.

Es necesario recordar que la regulación de las actividades económicas por parte de la normativa municipal aparece recogida en los acuerdos o actas de las sesiones del Cabildo o bien en las ordenanzas, definidas estas como la legislación emitida casi siempre por el mismo Cabildo municipal y destinada a reglamentar aspectos concretos y muchas veces singulares de la actividad económica ${ }^{31}$.

El proyecto Interreg culminó con la publicación de La empresa azucarera en Canarias. siglos $X V-X X$ en 2012, obra en la que Viña y Ronquillo realizaron el estudio global del primer ciclo del azúcar en Canarias.

En el proceso de descubrimiento y construcción del mundo atlántico —escriben en la Introducción-, los espacios insulares desempeñaron un papel de innegable importancia, pues la extensión de los países ibéricos comenzó siendo insular y sus imperios se asentarán, en buena medida, en esos espacios. Las islas que conforman la región macaronésica estuvieron estrechamente vinculadas a la caña de azúcar, cultivo que se adaptó perfectamente a las condiciones de estas, siendo Madeira y Canarias el puente para la expansión de este producto del Mediterráneo al Atlántico y su posterior implantación en el continente americano.

El objetivo que nos planteamos al analizar el primer ciclo del azúcar en Canarias —seguimos leyendo-, es presentar un trabajo de conjunto que aborde el significado que este producto tuvo para las islas, tanto desde el punto de vista económico como social y político, y para ello lo hemos estructurado en una serie de epígrafes en los que abordamos el marco institucional, un segundo apartado «de la plantación al ingenio», un tercer epígrafe relativo al elemento humano, personal cualificado, operarios y esclavos; con posterioridad abordaremos los productos obtenidos de la caña (azúcares y derivados), así como las rutas y mercados a los que fueron destinados estos productos, con especial incidencia en las colonias de mercaderes y su imbricación en la sociedad de las islas.

Como la obra posterior de ambas autoras ha puesto de manifiesto, después de este libro sus investigaciones en torno al azúcar han seguido dando sus frutos ${ }^{32}$. En el caso de Manoli, su estudio sobre los ingenios azucareros (2008) y sus concomitancias con la Inquisición (2012 y 2014), institución básica para conocer los orígenes de la sociedad canaria a la que dedicó también una parte importante de su investigación.

\section{LOS ORÍGENES DE LA INQUISICIÓN CANARIA EN EL MARCO DE LA HISTORIA ATLÁNTICA}

Esta línea de investigación de Manoli, cuyo primer trabajo profesional fue el de archivera municipal de Gáldar (1988-1990), concuerda plenamente con el título de este estudio en el que analizamos la obra de la historiadora sevillana. El libro de 1991, fruto de su tesina, presentada en

29 VIÑA (2015), pp. 76-99.

30 AZNAR y VIÑA (1990).

31 VIÑA (2013), pp. 397-425.

32 Como se evidencia en las publicaciones sobre el azúcar en el último decenio, véase, entre otras, VIÑA y otros (2014 y 2016). 
la Universidad de La Laguna, al igual que los trabajos posteriores, aborda también la creación de una sociedad nueva en el Atlántico medio que algunos han calificado de frontera ${ }^{33}$. Se relaciona con la integración mayor o menor de las minorías sociales a la nueva sociedad. Hace referencia, asimismo, a la configuración de su relación con la Corona de Castilla. Tiene que ver con la vinculación de Canarias y Sevilla, dado que el Tribunal da sus primeros pasos bajo la dependencia sevillana ${ }^{34}$. Guarda conexión con los ritos de fundación de nuevas instituciones ${ }^{35} \mathrm{y}$, por último, con la historia atlántica ${ }^{36}$.

Los estudios sobre la Inquisición en Canarias tienen su arranque en la obra de Agustín Millares Torres, que es la primera visión de conjunto de un tribunal del Santo Oficio español, según Fajardo Espínola, y referencia de los historiadores anglosajones que escribieron sobre la institución, por ejemplo, Lea, del que hay una reciente reedición de su obra en español ${ }^{37}$. Es indudable que los fondos documentales del Museo Canario y del Archivo Histórico Nacional han sido claves para el desarrollo historiográfico de esta institución a partir del momento del resurgir de la historiografía canaria (creación de la Sección de Historia de la Universidad de La Laguna y posteriormente del Departamento de Historia de la Universidad de Las Palmas de Gran Canaria). Manoli se incorporó a la investigación sobre las islas Canarias en el momento en que renacían los estudios sobre la Inquisición en Canarias, después de una década prodigiosa de publicaciones sobre el Santo Oficio en España (1976-1985) que, a decir de García Cárcel, significaron la regionalización de los estudios inquisitoriales ${ }^{38}$. Fue precisamente en el «Curso sobre problemas históricos de la Inquisición española», celebrado en la Universidad Internacional de Santander en agosto de 1976 - que, escribe José Antonio Escudero, fue la primera reunión científica sobre la Inquisición en Europa-, cuando se inició ese decenio creativo en el que se sucedieron congresos, seminarios, jornadas, erección de centros (Instituto de Historia de la Inquisición que se creó en 1984 y más tarde reconvertido en Instituto de Historia de la Intolerancia), publicaciones, etc. ${ }^{39}$. A ese curso de Santander, organizado por el propio Escudero, que tuvo como personaje central a Marcel Bataillon, asistieron Kamen, Tomás y Valiente, Tellechea, Henningsen, Cuenca Toribio, Contreras, García Cárcel, etc., que han sido figuras relevantes en el desarrollo posterior de los estudios inquisitoriales.

El trabajo Los orígenes de la Inquisición en Canarias, $1488-1526^{40}$ puede ser considerado pionero en las islas y a nuestro entender merece un mayor reconocimiento. Estaría en la línea de la constatación por parte de la historiografía inquisitorial de que el Santo Oficio «fue ante todo un Tribunal, o, mejor dicho, una serie de tribunales, dirigidos por un órgano políticoadministrativo de la monarquía, el llamado Consejo de la Suprema Inquisición» ${ }^{41}$.

En los estudios inquisitoriales podemos encontrar dos líneas fundamentales. De un lado, los estudios promovidos desde la historia del derecho por José Antonio Escudero ${ }^{42}$ — uno de los promotores del Instituto de Historia de la Inquisición-y Francisco Tomás y Valiente ${ }^{43}$. De otro, los emprendidos desde la historia general, cuyos nombres principales serían Escandell Bonet y Pérez Villanueva, autores de una monumental historia de la Inquisición española, en cuyo tomo I hay un capítulo dedicado a la historiografía de la Inquisición redactado por Pérez Villanueva ${ }^{44}$. Estos últimos, además, fundaron un Centro de Estudios Inquisitoriales.

Dentro de los estudios realizados desde el campo de la historia moderna hay que situar a Jaime Contreras $^{45}$, Jean Pierre Dedieu ${ }^{46}$ y Ricardo García Cárcel ${ }^{47}$, cuyas investigaciones en el campo

33 ANAYA (1991, 2006), FAJARDO (2006). VIÑA (2019), pp. 433-450.

34 WAGNER (1973), SOLERA (2014).

35 BETHENCOURT (1998).

36 CONTRERAS y MARTÍNEZ (2010), NAVARRO (2019).

37 FAJARDO (2003 y 2006).

38 Manuscrits, n. ${ }^{\circ} 13$, gener 1995, pp. 31-55.

39 ESCUDERO (2020): XVI. Agradecemos esta información al profesor Galván Rodríguez.

40 Trabajo realizado a partir de su Memoria de Licenciatura dirigida por el Dr. Aznar Vallejo.

41 ESCUDERO (2020), VIII.

42 ESCUDERO (2005).

43 Para la historiografía del tribunal canario, una versión reciente en GALVÁN (2016).

44 ESCANDELL BONET (1984-2000).

45 CONTRERAS (1993).

46 CONTRERAS Y DEDIEU (1980).

47 GARCÍA CÁRCEL y KHAMEN (1976), GARCÍA CÁRCEL (1984 y 1994). 
de las mentalidades, o desde la perspectiva de las víctimas, pueden relacionarse con los trabajos de Anaya Hernández y Fajardo Espínola para la historiografía insular.

La obra de la historiadora sevillana, en este campo de investigación, estaría a caballo entre ambas corrientes. Precisamente el primer valor que aporta Los orígenes de la Inquisición en Canarias es la preocupación desde la perspectiva Diplomática por los documentos del Museo Canario $^{48}$. Estamos ante un análisis político institucional en el que se atiende al período anterior a 1505, en el que se comisiona a determinados eclesiásticos desde Sevilla para que se ocupen de algunas denuncias. El traspaso de la institución y, por tanto, la creación del Tribunal, en 1505, responde a su utilización como instrumento de control de la monarquía, una vez concluida la conquista realenga. Este planteamiento se repetirá en el trabajo que consagrará a los conflictos jurisdiccionales en 2017: el personal humano, los recursos ${ }^{49}$, el territorio, los procedimientos empleados, los delitos castigados (religiosos, de carácter despreciativo contra la religión o directamente contra el Santo Oficio) y las sentencias, sin olvidarnos de los sentenciados. Al realizar el balance de la aportación historiográfica de Ronquillo no deja de sorprendernos que este libro apenas haya sido tenido en cuenta por la historiografía canaria, que sí se ha ocupado, sin embargo, del volumen más de divulgación, publicado en la Colección Guagua, también del Cabildo.

Relacionado con sus trabajos sobre la Inquisición mencionamos «El secuestro inquisitorial como fuente de conocimiento de la vida cotidiana ${ }^{50}$, junto a otras investigaciones donde une dos de sus líneas de investigación: azúcar e inquisición, lo que se evidencia en publicaciones como «El mundo del azúcar en la documentación inquisitorial canaria entre 1505-1526» ${ }^{51}$. En ellas nos muestra la aportación que las fuentes inquisitoriales proporcionan para el estudio del azúcar en Canarias en los primeros años de la colonización, así como para conocer la religiosidad de propietarios y trabajadores y cómo actuó la Inquisición sobre ellos.

\section{EDICIÓN DE FUENTES Y DOCUMENTOS HISTORIOGRÁFICOS}

Las fuentes documentales constituyen una referencia inexcusable en cualquier tipo de investigación. No podemos olvidar que su análisis nos permite reflexionar sobre distintos aspectos de la historia social, económica, política, etc., de una comunidad, por lo que la conservación y visibilidad de un corpus documental es básica para quienes nos acercamos a la historia de Canarias, pues, como señaló Priani, «el texto ocupa un lugar predominante como objeto primario de estudio, producción de conocimiento y diseminación ${ }^{52}$.

En sus investigaciones se ocupó de esta faceta de recuperación de fuentes documentales, ya fuera la trascripción, anotaciones y valoración de las fuentes escritas en algunos de sus trabajos, consciente de que los papeles conservados en los archivos conforman una parte muy importante de nuestro patrimonio documental.

Debe señalarse, dentro del área historiográfica, Introducción, transcripción y notas de la Topografia de fray José de Sosa (1994) ${ }^{53}$, tomando como base el original conservado en la Sociedad Cosmológica de Santa Cruz de La Palma y contrastado con la edición del Museo Canario, diferenciando las palabras o párrafos que figuran en el manuscrito y no en la primitiva edición. Este trabajo consta de una serie de anotaciones con la finalidad de informar de aquellos hechos que presentan diferencias sustanciales con otros cronistas y aclarar aspectos no explicados en el manuscrito realizado por este franciscano del siglo XVII sobre la historia de Gran Canaria, que, si bien presenta algunos errores cronológicos, constituye una referencia que deber ser tenida en cuenta entre los etnohistoriadores preocupados por la historia de las islas.

48 Cf. también ARANDA (1995).

49 Sirva como ejemplo la presencia del secretario del Tribunal desde principios del 500 o el control de la fe, edictos, testificaciones y pruebas documentales que en Canarias, entre 1499 y 1505, fueron publicadas y proclamadas, pp. 166 y 168 respectivamente. Cf. BETANCOR (2020), pp. 99-152.

50 RONQUILLO (1990), pp. 93-110.

51 RONQUILLO (2012), pp. 161-180.

52 PRIANI (2015).

53 RONQUILLO y VIÑA (1994). 
Sin duda, una referencia fundamental fue su trabajo sobre Repartimientos de Gran Canaria ${ }^{54}$ en colaboración con el Dr. Aznar Vallejo. Una obra de gran importancia para el análisis del repartimiento en Gran Canaria que, aparte de los bienes adjudicados (tierras, que constituyen el grueso del repartimiento, aguas, cuevas...), presenta un estudio diplomático y paleográfico de la documentación que compone este inmenso volumen. Este trabajo no se ciñe a la publicación de extractos de la documentación, sino a su transcripción, pero también lleva a cabo la descripción material del soporte, papel artesano, tipos de marcas, etc., así como el estudio diplomático con un análisis de la tipología documental presente en los repartimientos y, por supuesto, un análisis de los repartimientos con sus propias peculiaridades fruto de la originalidad de la repoblación. Analiza, asimismo, los tres distritos del repartimiento (Gáldar, Las Palmas y Telde), las concesiones individuales y colectivas donde priman las iniciativas particulares, aunque no faltan repartos impulsados por la autoridad pública.

El Libro del Repartimiento aporta, asimismo, datos sobre bienes aborígenes, el medio natural y producciones agrícolas, y presenta unos magníficos índices de lugares, materias y personas que nos permiten «navegar» por la transcripción íntegra de los 427 asientos cuyos límites cronológicos van de 1511 a 1558. Una obra de referencia fruto del buen hacer de la citada profesora.

No podemos dejar de aludir a la publicación de documentos que acompañan a algunos de sus trabajos como anexos y, sobre todo, su conocimiento de las fuentes inquisitoriales de los primeros años del establecimiento del Tribunal en Canarias que, en muchos casos aunque transcritos, no llegaron a editarse.

\section{ESTUDIOS DE LA MUJER}

Los estudios de género han sido uno de los campos de investigación que en las últimas décadas mayores aportaciones han realizado a la historiografía general y Canarias se ha incorporado a esta nueva corriente con numerosos estudios que abarcan desde la Prehistoria a la época actual. Manuela Ronquillo no fue ajena a esta corriente historiográfica, en la que participó sin abandonar sus líneas prioritarias de investigación. Así, los inicios de su investigación sobre este colectivo están vinculados con la primera etapa de colonización del archipiélago, en particular con «El ajuar de la casa urbana en las islas Canarias a fines de la Edad Media» ${ }^{55}$, en el que nos muestra la similitud de objetos en los hogares analizados, independientemente del estatus de sus propietarios, primando en todos ellos la funcionalidad y destacando el importante papel de la mujer en la formación del ajuar.

Investigaciones que continuaron como lo demostró en el año 2000 con la publicación «Mujer e Inquisición en Canarias a fines de la Edad Media» ${ }^{56}$, en la que muestra cómo la mujer llegaba a contactar con la Inquisición, su espacio y su palabra, así como las testigos y denunciantes y la represión ejercida sobre este colectivo. Esta temática se amplía en una publicación posterior en la Revista de Historia Canaria: «Algunas consideraciones de los jueces eclesiásticos sobre las actitudes de las mujeres de las Islas Canarias a fines de la Edad Media» ${ }^{57}$.

Este perfil de investigación de la Dra. Manuela Ronquillo se había iniciado a raíz de su incorporación al «Aula de la Mujer» de la $\mathrm{ULPGC}^{58}$, dentro del «Seminario Mujer y Cultura» vinculado al Departamento de Ciencias Históricas. Desde entonces, primero desde la secretaría y después desde la dirección junto a la profesora titular de Historia Antigua, la Dra. Rosa María Sierra del Molino, puso en marcha diez seminarios consecutivos desde 1995 a 2004, tarea ardua pero gratificante; pues se contó con la participación en ellos de relevantes investigadoras e investigadores universitarios, nacionales e internacionales que han dedicado sus estudios a la perspectiva de Género ${ }^{59}$. Como conferenciante, la Dra. Ronquillo aportó en el I Seminario una

54 RONQUILLO y AZNAR (1998).

55 RONQUILLO (1992), pp. 37-42.

56 RONQUILLO (2000), pp. 199-224.

57 RONQUILLO (2005), pp. 245-262.

58 Fundada en 1994 por las profesoras de la ULPGC, la Dra. MARÍA ASUNCIÓN GONZÁLEZ DE CHÁVEZ (Seminario «Mujer y Salud»), la Dra. ROSA MARÍA SIERRA DEL MOLINO (Seminario «Mujer y Cultura») y Dña. ANA DORESTE SUÁREZ (Seminario «Mujer, Derecho y Sociedad»).

59 Es necesario significar aquí toda la labor realizada por Manuela y su compañera Rosa para llevar, a buen puerto, la consecución de los diez Seminarios; financiados por antiguo Instituto de la Mujer de Madrid (Organismo 
espléndida comunicación titulada «La mujer ante los jueces eclesiásticos a fines de la Edad Media» ${ }^{60}$, al lado de otras comunicaciones en las que se hizo una revisión del colectivo femenino, analizado desde diferentes ámbitos de actuación interdisciplinares y todas las épocas históricas. El conjunto de seminarios «Mujer y Cultura» enriqueció la mirada, desde el Género, a sus participantes, principalmente a sus alumnas y alumnos. Sus frutos se consolidaron años después.

Pero, siguiendo la trayectoria del esfuerzo realizado por la Dra. Ronquillo y por su compañera, la Dra. Sierra, para traer a la Universidad de Las Palmas de Gran Canaria a las personas más representativas en los estudios de Género - nacionales y extranjeras-, no tardó mucho en tener una fértil respuesta. En el año 2001, después de haber concluido el VII Seminario, la AEIHM (Asociación Española de Investigación Histórica de las Mujeres), las convocó para llevar a cabo en Las Palmas el IV Taller de esta asociación titulado «Reuniones de Mujeres a lo largo de la Historia». Era la primera vez que la más importante asociación sobre investigación histórica de Género en el ámbito nacional celebraba en Canarias un acontecimiento de tal magnitud. El Comité Organizador del evento estuvo formado por Manuela Ronquillo y Rosa Sierra, de nuevo una misión laboriosa pero agradecida; en esta ocasión fue la Casa de Colón (Las Palmas de Gran Canaria), gracias a la amabilidad y predisposición de su directora, Dña. Elena Acosta Guerrero, el entrañable contexto en el que se celebró el IV Taller de la AEIHM. Sin embargo, Manuela no solo se ocupó de organizar con éxito esta convocatoria, sino también de presentar una deliciosa comunicación titulada «Pretextos, excusas y otras necesidades. Reuniones de mujeres en la Edad Media» ${ }^{61}$, en la que puso de manifiesto las magistrales argucias, componendas y artimañas que el colectivo femenino utilizó, como si de un juego de artificio se tratase, para lograr su objetivo: reunirse fuera de la mirada del colectivo varón.

Asimismo, otra de las consecuencias del trabajo realizado en este camino hacia la igualdad fue la participación de la Dra. Ronquillo en dos proyectos de investigación dirigidos por la Dra. Rosa

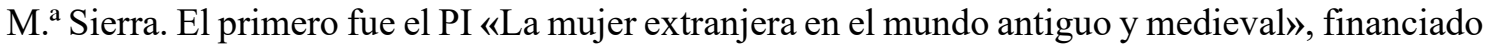
por el Instituto Canario de la Mujer y los Fondos Europeos FEDER (2002-2003), cuyo resultado fue la elaboración en colaboración de un trabajo de investigación titulado Mujeres extranjeras en el mundo antiguo y medieval, en Edición doméstica-Instituto Canario de la Mujer (2003). En este estudio, Manuela concluye:

$\mathrm{Si}$, para la mujer medieval, en general, no puede hablarse de una 'uniformidad femenina, salvo teórica'; sino de diferentes tipos de mujeres; en el caso de las extranjeras abordar su situación es una tarea desesperante por la parquedad de la información. Si eran mujeres de extranjeros con estatuto jurídico en la ciudad, los problemas se solventan a través de sus cónsules, por lo que no se nos ha transmitido; si viven solas, solo se las presenta como integrantes del vecindario respectivo con pocos datos sobre su vida que -caso de no haber revisado todos los padroneshubiesen pasado desapercibidas ${ }^{62}$.

El otro PI en el que intervino Manuela fue $<<$ Mujeres en movimiento $>>$, también financiado por el Instituto Canario de la Mujer y el Fondo Social Europeo (2005-2006); fruto de ello fue la publicación del libro coordinado por Rosa Sierra Mujeres en movimiento. Historia y literatura, publicado en el año 2006. En esta edición se reunió una selección de las comunicaciones presentadas a los seminarios «Mujer y Cultura», consiguiendo aunar a investigadores canarios,

del Gobierno de la Nación, adscrito entonces al Ministerio de Asuntos Sociales), el Instituto de la Mujer de Canarias y los Fondos Europeos FEDER, celebrados en la Facultad de Geografía e Historia de la ULPGC: I Seminario Universitario «Mujer y cultura», mayo 1995; II Sem. Univ. «Mujer y poder en las sociedades precapitalistas», febrero-marzo 1996; III Sem. Univ. «Mujer, sexualidad y marginalidad en el proceso histórico», abril 1997; IV Sem. Univ. «Mujer y trabajo», abril-mayo 1998; V Sem. Univ. «La Mujer y el saber», abril 1999; VI Sem. Univ. «La Mujer, una mirada masculina», mayo-junio 2000; VII Sem. Univ. «La Mujer diferente», marzo 2001; VIII Sem. Univ. «Mujer y alteridad», mayo 2002; IX Sem. Univ. «La mujer en los conflictos bélicos», abril 2003; X Sem. Univ. «Summarium": una década sobre investigaciones interdisciplinares de Género en la ULPGC, 1995-2004».», mayo-junio 2004.

60 Esta conferencia se transformó en uno de los artículos mencionados más arriba; véase, supra, nota 62.

61 RONQUILLO (2001), «Pretextos, excusas y otras necesidades. Reuniones de mujeres en la Edad Media», comunicación presentada en el IV Taller de la AEIHM: Reuniones de Mujeres a lo largo de la Historia, celebrado en la Casa de Colón, en Las Palmas de Gran Canaria, en noviembre de 2001.

62 SIERRA y RONQUILLO (2003), p. 17. 
como la Dra. Ana Viña, peninsulares y extranjeros. Con todo ello, se ha pretendido, tal y como expresa Manuel Lobo en el prólogo «ofrecer una oportunidad para la reflexión en torno a la situación de la mujer vista de una manera poliédrica, abordando géneros como la historia y la literatura en todas sus vertientes». Unido a estos estudios destacamos el capítulo aportado por Manuela Ronquillo: «Repertorio bibliográfico. Historia de las mujeres y de las relaciones de género en la ULPGC» ${ }^{63}$; así como sus aportaciones a los seminarios «Mujer y Cultura» del Aula de la Mujer de la ULPGC que quedan al margen de las comunicaciones, pues se trata de recoger un muestrario útil, «elaborado para que sirva de apoyo tanto para la investigación como para la docencia», en palabras de la propia Manuela.

Como antes se ha comentado, algunas de las consecuencias más agradables de esta inmersión en el Género se vieron reflejadas, años después, en la dirección de tesis doctorales, como fue la codirección de Manuela junto a Rosa y otro compañero de Filología Inglesa, el Dr. José Manuel Rodríguez Herrera, de una tesis doctoral leída en 2016 y cuyo tema versó sobre la figura de la «Femme fatal» en el cine negro americano ${ }^{64}$. Pero el fatum no ha querido que viera concluida otra tesis de Género que dirigía en solitario y que está vinculada con sus investigaciones sobre la mujer en el mundo medieval ${ }^{65}$. Espacio y tiempo de la historia que tanto veneraba y con el que logró seducirnos para siempre.

\section{MENTALIDADES. RELIGIÓN Y ESPIRITUALIDAD}

La religiosidad popular ha sido uno de los aspectos más trabajados de la historia de las mentalidades en los últimos años, en los que se han incorporado a estos estudios nuevas técnicas y metodologías. No obstante, aún sigue en pie el debate de si la religiosidad popular es distinta a la oficial, a la que a menudo se opone, o si por el contrario no existe ningún tipo de incompatibilidad entre la denominada religiosidad popular y la impuesta por la Iglesia. El interés mostrado por esta profesora sobre esta temática es patente en algunas de sus publicaciones al plantear la forma en que las personas en los albores de la colonización del archipiélago se enfrentaban a la muerte, como vemos, entre otros, en el artículo, en colaboración con Ana Viña, "Actitud ante la muerte a través de los testamentos canarios del primer cuarto del siglo XVI» ${ }^{66}$, donde se concluye, tras el análisis de numerosos testamentos y por comparación con otros ámbitos, que la muerte, como una de las angustias colectivas que la Iglesia intenta paliar con ritos, es igual en hombres y mujeres, pero también que estamos ante una religiosidad más de temor al juicio tras la muerte, o el Final, y a la condenación eterna, que de amor y caridad verdadera. Ese ideal cristiano de igualdad tras la muerte no se cumplía, como que no hay referencias al conocimiento del más allá por el hombre, solo que sobre todos planea la idea de almas expiando culpas, la suya también cuando llegue, a las que se puede ayudar con los recursos creados por la Iglesia.

Otro de los trabajos en los que se interesó por esta temática fue «Pervivencias de rituales canarios tras la conquista bajomedieval en la documentación inquisitorial», en el que puso de manifiesto, a través de las fuentes inquisitoriales, cómo en la primera etapa de colonización del archipiélago siguieron perviviendo algunos rituales de la población insular, sobre todo en las zonas más alejadas del Real de Las Palmas ${ }^{67}$.

Incluimos en este apartado un análisis de las ermitas de Gran Canaria tras la conquista, en colaboración con Luz Marina Delgado ${ }^{68}$, en el que una vez asentada la población en las islas se

63 Publicado en SIERRA DEL MOLINO (2006), pp. 215-282.

64 SÁNCHEZ DEL MOLINO, IRÍA FLAVIA (2016): La figura de la "Femme Fatale" en el cine negro americano: "Double Indemnity" (Billy Wilder, 1944). Directora, SIERRA DEL MOLINO R. M. y codirectores, RONQUILLO RUBIO M. y RODRÍGUEZ HERRERA J. M., Universidad de Las Palmas de Gran Canaria.

65 Se trata de la tesis que dirigía la D. ${ }^{a}$ Ronquillo a la doctoranda Carmen Heredia Heredia, El papel de la mujer medieval en las fronteras castellanas, dentro del Programa de Doctorado «Islas Atlánticas: Historia, Patrimonio y Marco Jurídico Institucional» de la ULPGC.

66 RONQUILLO y VIÑA (2000), pp. 2309-2334.

67 RONQUILLO y VIÑA (2008), pp. 203-212.

68 DELGADO y RONQUILLO (2018), pp. 1-24. 
investigó la causa de la creación de las ermitas. Un trabajo que se une a una serie de estudios que se han venido realizando sobre la primera organización eclesiástica del archipiélago ${ }^{69}$.

\section{CONCLUSIONES}

La contribución historiográfica que la Dra. Ronquillo Rubio - como hemos señalado, sabiéndose integrar en diversos equipos y proyectos- ha realizado a la historia atlántica y especialmente a la historia social en el período bajomedieval y los albores del mundo moderno se estructura en tres grandes líneas de investigación: minorías sociales y profesionales y los procesos de integración en sociedades nuevas, el Atlántico y el azúcar y los orígenes de la Inquisición canaria, como hemos analizado a lo largo de estas páginas.

No queremos finalizar esta aproximación sin dedicar unas líneas a la docencia que impartió la Dra. Ronquillo en la ULPGC, en grados, máster y doctorado, donde su recuerdo permanecerá en el alumnado y, sobre todo, en aquellas personas a las que dirigió en TFG, TFM y muy especialmente en tesis doctorales, algunas de las cuales, desafortunadamente, no ha podido ver finalizadas. Ese recuerdo seguirá presente, asimismo, en sus compañeros y compañeras del Departamento y en todos aquellos que nos enorgullecemos de haber sido sus amigos/as y colaboradores.

Concluimos este trabajo sobre la contribución historiográfica de la Dra. Ronquillo Rubio con un reconocimiento a las investigaciones que llevó a cabo y un recuerdo emocionado de quienes tuvimos la fortuna de conocerla y compartir con ella algunas de sus investigaciones.

\section{REFERENCIAS ESPECÍfICAS DE LA DRA. MANOLI RONQUILLO RUBIO}

Minorías sociales y profesionales: los procesos de integración en sociedades nuevas

LUXÁN MELÉNDEZ, S. de y RONQUILLO RUBIO, M. (1995). «Aportación al estudio de la población extranjera de Sevilla a mediados del siglo XVII». En Actas del II Congreso de Historia de Andalucía: Córdoba, 1991, Vol. 7 (Historia Moderna I), pp. 463-471.

RONQUILLO RUBIO, M. (2002). «La promoción de una familia de artesanos vascos en el siglo XV. Nicolás Martínez de Durango, Mercader, Jurado y Mayordomo del Cabildo Sevillano». Archivo hispalense: Revista histórica, literaria y artística, tomo 85, núm. 259-260, pp. 83-114.

RONQUILLO RUBIO, M. (2004). «Los vascos en Canarias durante la época señorial». En $X V$ Coloquio de historia canario-americana / coord. por Francisco Morales Padrón, pp. 20582072.

RONQUILLO RUBIO, M. (2004). Los vascos en Sevilla y su tierra durante los siglos XIII, $X I V$ y XV: fundamentos de su éxito y permanencia. Bilbao: Diputación Foral de Bizkaia.

RONQUILLO RUBIO, M. (2007). «Los gallegos en Sevilla en el siglo XV. Cuestiones previas: número, ubicación, niveles socio-profesionales y relacionales». Medievalismo, núm. 17, pp. 151-186.

RONQUILLO RUBIO, M. (2012). «La presencia vasca en las Islas Canarias a raíz de la conquista realenga (1476-1500)». En Mundos medievales: espacios, sociedades y poder: homenaje al profesor José Ángel García de Cortázar y Ruiz de Aguirre. Cantabria: Publicaciones de la Universidad de Cantabria, vol. 2, pp. 1851-1862.

RONQUILLO RUBIO, M. (2015). «Mercaderes vascos en la Sevilla bajomedieval». En SOLÓRZANO TELECHEA, J. A. y SICKING, L. (coords.), Diplomacia y comercio en la Europa atlántica medieval. Logroño: Instituto de Estudios Riojanos, pp. 245-275.

RONQUILLO RUBIO, M. (2019). «Mercaderes vascos en la Baja Andalucía y Canarias (fines del siglo XV-1520)». En FERNÁNDEZ CHAVES, M. F.; PÉREZ GARCÍA, R. y

69 AZNAR (1986), VIÑA (1990), LOBO (2006). 
PÉREZ, B. (coords.), Mercaderes y redes mercantiles en la Península Ibérica. Siglos XVXVIII. Lisboa: Cátedra de Estudios Alberto Beneviste. Sevilla: Editorial Universidad de Sevilla; París: Éditions Hispaniques, pp. 129-154.

\title{
El Atlántico y el azúcar
}

RONQUILLO RUBIO, M. (2008). «Ingenios azucareros en la colonización canaria: 14781526. Localización espacial y organización del espacio en Gran Canaria». En VIÑA BRITO, A.; GAMBÍN GARCİA, M. y CHINEA BRITO, C. D. (coords.), Azúcar. Los ingenios en la colonización canaria (1487-1525). Santa Cruz de Tenerife: Museo de Historia y Antropología de Tenerife, pp. 99-112.

RONQUILLO RUBIO, M. (2012). «El mundo del azúcar en la documentación inquisitorial canaria entre 1505 y 1526». En VIÑA BRITO, A. y CORBELLA, D. (eds.), La ruta azucarera atlántica: Historia y documentación. La Laguna-Funchal: Servicio de Publicaciones de la Universidad de La Laguna, pp. 161-180.

RONQUILLO RUBIO, M. (2014). «Propietarios del azúcar y sus relaciones con la Inquisición de Canarias (1505-1526)». En VIÑA BRITO, A. (ed.), Azúcar y mecenazgo en Gran Canaria. El oro de las Islas, siglos XV-XVI. En Jornadas Azúcar y mecenazgo (Casa de Colón octubre de 2013). Las Palmas de Gran Canaria: Cabildo de Gran Canaria, pp. 51-72.

VIÑA BRITO, A. y RONQUILLO RUBIO, M. (2004). «El control normativo del azúcar en Canarias». En III Seminario Internacional sobre a Historia do Açucar. O Açúcar e o quotidiano. Funchal, pp. 179-206.

VIÑA BRITO, A. y RONQUILLO RUBIO, M. (2006). «El primer ciclo del azúcar en Canarias. Balance historiográfico». En XVI Coloquio de Historia Canario- Americana, pp. 1673-1696.

VIÑA BRITO, A. y RONQUILlO RUBIO, M. (2009). "Canarias en el Primer Ciclo del Azúcar». En LUXÁN MELÉNDEZ, S. de y VIÑA BRITO, A. (dirs.), La empresa azucarera en canarias. siglos $X V-X X$. Las Palmas de Gran Canaria Destilerías Arehucas y Ayuntamiento de los Llanos de Aridane, pp. 13-102.

\section{Los orígenes de la Inquisición}

RONQUILlO RUBIO, M. (1990). El tribunal de la Inquisición en Canarias (1505-1526). Las Palmas de Gran Canaria: Ediciones del Cabildo Insular de Gran Canaria.

RONQUILlO RUBIO, M. (1991). Los orígenes de la Inquisición en Canarias, 1488-1526. Las Palmas de Gran Canaria: Cabildo Insular de Gran Canaria.

RONQUILLO RUBIO, M. (1992). «El secuestro inquisitorial como fuente de conocimiento de la vida cotidiana». En IX Coloquio de Historia Canario-Americana, vol. 2, pp. 93-110.

RONQUILLO RUBIO, M. (2017). "Conflictos jurisdiccionales en los inicios de la inquisición canaria (fines del siglo XV-principios del XVI)». Revista de Historia Canaria, núm. 199, pp. 59-79.

\section{Edición de documentos e Historiografía}

RONQUILlO RUBIO, M. y VIÑA BRITO, A. (1994). Fray José de Sosa. Topografía de la isla afortunada de Gran Canaria. Introducción, transcripción y notas. Las Palmas de Gran Canaria: Cabildo de Gran Canaria.

RONQUILLO RUBIO, M. y AZNAR VALLEJO, E. (1998). Repartimientos de Gran Canaria. Estudio, transcripción y notas. Las Palmas de Gran Canaria: Cabildo de Gran Canaria.

\author{
Estudios de Género
}


RONQUILLO RUBIO, M. (1992). «El ajuar de la casa urbana en las islas Canarias a fines de la Edad Media». Vegueta 0, pp. 37-42.

RONQUILLO RUBIO, M. (2000). «Mujer e Inquisición en Canarias a fines de la Edad Media». Revista de Historia Canaria, núm. 182, pp. 199-224.

RONQUILLO RUBIO, M. (2005). «Algunas consideraciones de los jueces eclesiásticos sobre las actitudes de las mujeres de las Islas Canarias a fines de la Edad Media». Revista de Historia Canaria, núm. 187, pp. 245-262.

RONQUILLO RUBIO, M. (2006). «Repertorio Bibliográfico. Historia de las mujeres y de las relaciones de género en la Universidad de Las Palmas de Gran Canaria». En SIERRA DEL MOLINO, R. M. (coord.), Mujeres en movimiento: Historia y literatura. Las Palmas de Gran Canaria: Universidad de Las Palmas de Gran Canaria, pp. 215-282.

SIERRA, R. M. y RONQUILLO, M. (2003). Mujeres extranjeras en el mundo antiguo y medieval. Las Palmas de Gran Canaria: Edición doméstica-Instituto Canario de la Mujer.

\section{Mentalidades}

DELGADO HERNÁNDEZ, L. M. y RONQUILLO RUBIO, M. (2018). «Aproximación al estudio de las ermitas: análisis y tipología funcional de las ermitas de Gran Canaria de fines del siglo XV a principios del XVI». Anuario de Estudios Atlánticos, núm. 65, pp. 065-001. Recuperado de http://anuariosatlanticos.casadecolon.com/index.php/aea/article/view/10239

RONQUILLO, M. y VIÑA, A. (2000). «Actitud ante la muerte a través de los testamentos canarios del primer cuarto del siglo XVI». En XIII Coloquio de Historia Canario-Americana, pp. 2309-2334.

RONQUILLO, M. y VIÑA, A. (2008). «Pervivencias de rituales canarios tras la conquista bajomedieval en la documentación inquisitorial». En ATOCHE, P.; RODRÍGUEZ, C. y RAMÍREZ, M. ${ }^{a}$ A. (eds.) Mummies and Science. World Mummies Research. Proceedings of the VI World Congress on Mummy Studies. S/C de Tenerife: Academia Canaria de la Historia, pp. 203-212.

\section{BIBLIOGRAFÍA GENERAL CITADA EN EL TEXTO}

ANAYA HERNÁNDEZ, L. A. (1991). «Los judeoconversos y los orígenes de la Inquisición canaria». En Congreso Internacional judios y conversos en la Historia, Rivadabia, pp. 13-28.

ANAYA HERNÁNDEZ, L. A. (1992). «Los judeoconversos y la creación de la Inquisición canaria a través de un documento inédito». Tebeto. Anuario del Archivo Histórico Insular de Fuerteventura, núm. 4, pp. 11-28.

ANAYA HERNÁNDEZ, L. A. (2006). «Creación y primeros años del Tribunal del Santo Oficio de la Inquisición de las Islas Canarias». En XVI Coloquio de Historia CanarioAmericana (2004), pp. 2018-2031.

ARANDA MENDÍAZ, M. (1995). «Los manuscritos españoles en el Museo Británico: Notas sobre el Tribunal de la Inquisición de Canarias y el Consejo de la Suprema durante los siglos XVI, XVII y XVIII». Revista de Ciencias Jurídicas, núm. 0, pp. 9-22.

AZNAR VALLEJO, E. (1982). «Las relaciones comerciales entre Andalucía y Canarias a finales del siglo XV y comienzos del XVI». Actas del II Coloquio de Historia Medieval Andaluza. Hacienda y comercio, pp. 269-282.

AZNAR VALLEJO, E. (1986). La integración de las islas Canarias en la Corona de Castilla (1478-1526). La Laguna: Universidad de La Laguna.

AZNAR VALLEJO, E. (1986). «La colonización de las Islas Canarias en el siglo XV». En la España Medieval, núm. 8. Estudios en memoria de D. Claudio Sánchez- Albornoz, vol. 1, pp. 195-218. 
AZNAR VALLEJO, E. y VIÑA BRITO, A. (1990). «El azúcar canario, escala entre dos mundos». En MALPICA, A. (coord.), La caña de azúcar en la época de los grandes descubrimientos. Motril-Granada: Universidad de Granada, pp. 173-188.

AZNAR VALLEJO, E.; CORBELlA, D.; PICO, B. y TEJERA, A. (2006). Le Canarien. Retrato de dos mundos. La Laguna: Instituto de Estudios Canarios

BAUCELS MESA, S. (2004). Crónicas, historias, relaciones y otros relatos: las fuentes narrativas del proceso de interacción cultural entre aborígenes canarios y europeos (siglos XIV a XVII). Las Palmas de Gran Canaria: Caja Rural de Canarias-El Museo Canario.

BETANCOR, F. (2020). «iRecórranse los registros! El archivo inquisitorial canario ¿Un instrumento para el control social?». En BELLO JIMÉNEZ, V. (coord.), Archivos para gobernar el mundo. Las Palmas de Gran Canaria: Mercurio, pp. 99-152.

BETHENCOURT MASSIEU, A. (1977). «Desarrollo de las investigaciones históricas tras Millares Torres». En Historia general de las Islas Canarias de Agustín Millares Torres. Las Palmas de Gran Canaria: Edirca, pp. 59-72.

BETHENCOURT, F. (1998). La Inquisición en la época moderna. España, Portugal, Italia, siglos $X V X X$. Madrid: Akal.

CANSINO Y CASAFONDA, R. (1751). Nuevo Mapa. Descripción iconológica del mundo abreviado. Real Máscara... Sevilla.

https://repositorio.bde.es/handle/123456789/3041

CARANDE, R. ([1975] 2006). Sevilla, fortaleza y mercado. Las tierras, las gentes y la administración de la ciudad en el siglo XIV. Sevilla: Colegio Oficial de Aparejadores y Arquitectos Técnicos de Sevilla.

CONTRERAS CONTRERAS, J. (1993). «Los modelos regionales de la inquisición española. Consideraciones metodológicas». Problemas actuales de la historia. Salamanca: Publicaciones de la Universidad de Salamanca, pp. 83-98.

CONTRERAS CONTRERAS, J. y DEDIEU, J. P. (1980). «Geografía de la Inquisición Española. La formación de los distritos (1470-1820)». Hispania, vol. 40, núm. 1, 144, pp. 37-94.

CONTRERAS CONTRERAS, J. y MARTÍNEZ CODÉS, M. R. (2010). «Hacia una Historia Atlántica: visiones religiosas compartidas». Anuario de Estudios Americanos, núm. 67, 1, enero-junio, pp. 189-207.

CREYGHTON, C. (2016). «La survivance de Michelet: Historiographie et politique en France depuis 1870». Recuperado de

https://dare.uva.nl/search?identifier=1839fcc1-beb2-4dd9-9dd2-cd8a39fb4324 [Fecha de consulta: 6/5/2020].

ELLIOTT, J. H. (2000). «En búsqueda de la historia atlántica». Conferencia de apertura del XIV Coloquio de Historia Canario-Americana, pp. 20-36.

ELLIOTT, J. H. (2012). «El atlántico español y el atlántico luso: divergencias y convergencias». En XX Coloquio de Historia Canario-Americana,

http://coloquioscanariasamerica.casadecolon.com/index.php/CHCA/issue/view/269

ESCANDELL BONET, B. y PÉREZ VILLANUEVA, J. (dirs.) (1984-2000). Historia de la Inquisición en España y América. Madrid: Biblioteca de Autores Cristianos.

ESCUDERO LÓPEZ, J. A. (2005). Estudios sobre la Inquisición. Madrid: Marcial Pons.

ESCUDERO LÓPEZ, J. A. (2020). «Presentación» a Henry Charles LEA, Historia de la Inquisición Española. Madrid: Boletín Oficial del Estado, Fundación Universitaria Española, Instituto de la Intolerancia.

FAJARDO SPÍNOLA, F. (2003). Las víctimas del Santo Oficio: tres siglos de actividad de la Inquisición de Canaria. Las Palmas de Gran Canaria: Fundación de Enseñanza Superior a Distancia.

FAJARDO SPÍNOLA, F. (2006). «Inquisición y sociedad en Canarias. Trayectoria y perfil del tribunal insular». En XVI Coloquio de Historia Canario-Americana, pp. 2072-2087.

FARRUJIA DE LA ROSA, A. J. (2009-2010). «Canarias y el Norte de África desde una perspectiva historiográfica y arqueológica». Revista Tabona, núm. 18, pp. 63-90.

GALVÁN RODRÍGUEZ, E. (2016). «Una perspectiva del tribunal de la Inquisición de Canarias». Revista de la Inquisición (intolerancia y derechos humanos), núm. 20, pp. 11-36. 
GARCÍA CÁRCEL, R. (1984). «El período fundacional. Las primeras estructuras del Santo Oficio: el funcionamiento estructural de la Inquisición inicial». En ESCANDELL BONET, B. y PÉREZ VILLANUEVA, J. (dirs.), Historia de la Inquisición en España y América. Madrid: Biblioteca de Autores Cristianos, vol. 1, pp. 405-426.

GARCÍA CÁRCEL, R. (1994). «Orígenes y naturaleza de la Inquisición». En PRADELLS NADAL, J. y HINOJOSA MONTALVO, R. (coords.), 1490, en el umbral de la modernidad: el Mediterráneo europeo y las ciudades en el tránsito de los siglos XV-XVI. Valencia: Generalitat Valenciana, vol. 1, pp. 425-436.

GARCÍA CÁRCEL, R. y KAMEN, H. (1976). Orígenes de la Inquisición española. El Tribunal de Valencia, 1478-1530. Barcelona: Península.

GARCÍA FERNÁNDEZ, M. N. (2005). Comunidad extranjera y puerto privilegiado. Los británicos en Cádiz en el siglo XVIII. Cádiz: Servicio de Publicaciones de la Universidad de Cádiz.

GARCÍA FERNÁNDEZ, M. N. (2006). Comerciando con el enemigo: el tráfico mercantil anglo-español en el siglo XVIII (1700-1765). Madrid: Consejo Superior de Investigaciones Científicas.

GONZÁLEZ PÉREZ, T. (2002). «Canarias en la historiografía regional». Historia de la Educación. Revista Interuniversitaria, núm. 21, pp. 215-240.

GONZÁLEZ ZALACAÍN, R. (2016). «Diplomacia y comercio en la Europa Atlántica Medieval». Espacio, Tiempo y Forma. Serie III, Historia Medieval, núm. 29, pp. 869-873.

LA INQUISICIÓ A DEBAT, Manuscrits, núm. 13, gener 1995, pp. 31-55 [En la mesa redonda intervinieron: José Luis Martín, Ricardo García Cárcel, Jaime Contreras, Jea-Pierre Dedieu, Henry Kamen, y Francisco Tomás y Valiente].

LOBO CABRERA, M. (1993). «Vascos en el comercio canario-americano: los Narea», $I X$ Coloquio de Historia Canario-Americana (1990). Las Palmas, tomo 2, pp. 551-565.

LOBO CABRERA, M. (2004). «Las Relaciones comerciales entre Canarias y País Vasco».

En XV Coloquio de Historia Canario-Americana, pp. 807-814.

LOBO CABRERA, M. (2006). «Las primeras ermitas de Las Palmas». En LÓPEZ GARCÍA, J. S. y HERNÁNDEZ GUTIÉRREZ, A. S. (coord.), Miscelánea, Homenaje al doctor Ramón López Caneda. La Laguna (Tenerife), Universidad de Las Palmas de Gran Canaria.

LUXÁN MELÉNDEZ, S. de (1993). La historiografía canaria y la historia económica. Materiales de estudio. Las Palmas de Gran Canaria: Cuadernos Canarios de Ciencias Sociales (CIES).

LUXÁN MELÉNDEZ, S. de (1997). «Las dificultades de la empresa editorial en Canarias: alegrías y sinsabores de la IV edición de la Historia General de las Islas Canarias de A. Millares Torres (1974-1981), un episodio de la transición democrática». En MILLARES CANTERO, A.; LOBO CABRERA, M. y ATOCHE PEÑA, P. (coords.), Homenaje a Celso Martín de Guzmán (1946-1994). Las Palmas de Gran Canaria: Servicio de Publicaciones de la Universidad de Las Palmas de Gran Canaria, pp. 215-230.

LUXÁN MELÉNDEZ, S. de (2004). «Historia Económica e Historia Atlántica: algunas reflexiones sobre publicaciones recientes». Vegueta, núm. 8, pp. 251-290.

MACÍAS HERNÁNDEZ, A. (2011). «Canarias, 1800-2000: la singularidad de la historia económica isleña». Historia Contemporánea, n. ${ }^{\circ}$ 42, pp. 225-259.

MARTÍN DE GUZMÁN, C. (1990). «Últimas tendencias metodológicas de la historiografía canaria». En VII Coloquio de Historia Canario-Americana, pp. 145-257.

MIRANDA CALDERÍN, S. (2017). Orígenes y evolución del Régimen Económico y Fiscal de Canarias (REF) Tomo I. El origen histórico y la Hacienda Real, siglos XV y XVI. Las Palmas de Gran Canaria: Universidad de Las Palmas de Gran Canaria, Cátedra REF.

MORALES LEZCANO, V. (1996). «La historiografía canaria desde el 98: las relaciones con el mundo exterior». En Estudios de Historiografía Regional. Jornadas en homenaje a Agustín Millares Torres. Las Palmas de Gran Canaria: Real Sociedad Económica de Amigos del País, pp. 213-236. 
MURILLO JIMÉNEZ, R. (2014-2015). La presencia vasca en las Islas Canarias a raiz de la conquista realenga. Trabajo Fin de Grado de la Universidad de La Laguna, dirigido por Ana Viña Brito y Juan Manuel Bello León.

https://riull.ull.es/xmlui/bitstream/handle/915/1333/LA\%20PRESENCIA\%20VASCA\%20

EN\%20CANARIAS\%20A\%20RAIZ\%20DE\%20LA\%20CONQUISTA\%20REALENGA.pd

f? sequence $=1$

NAVARRO MEDINA, E. (2019). Los inicios de la Inquisición en territorio de ultramar. Primer siglo de actividad del Santo Oficio en Canarias (1488-1597). Trabajo de Fin de Grado de la Facultad de Derecho de la Universidad de La Laguna, tutorizado por D. ${ }^{a}$ María Teresa Manescau Martín.

https://riull.ull.es/xmlui/bitstream/handle/915/16425/Los\%20inicios\%20de\%20la\%20Inqui sicion $\% 20$ en $\% 20$ territorio $\% 20 \mathrm{de} \% 20$ ultramar.\%20Primer\%20siglo $\% 20 \mathrm{de} \% 201 \mathrm{a} \% 20$ activida d\%20del\%20Santo\%20Oficio\%20en\%20Canarias\%20\%281488-

$1597 \% 29$.pdf?sequence $=1 \&$ isAllowed $=\mathrm{y}$

PALENZUELA DOMÍNGUEZ, N. (2003). Los mercaderes burgaleses en Sevilla a fines de la Edad Media. Sevilla: Universidad de Sevilla.

PRIANI, E. (2015). «El texto digital y la disyuntiva de las humanidades digitales». En Palabras Clave DOI 105294/pacla.2015.18.4.11

RÉGULO PÉREZ, J. (1981). «La historiografía canaria después de Viera y Clavijo». En VIERA Y CLAVIJO, J., Noticias de la Historia de Canarias. Madrid, 3, pp. 89-99.

SOLERA CAMPOS, C. M. (2014). «Los progresos de la inquisición en Sevilla (14781484)». En Inquisición. XV Jornadas de Historia en Llerena. Sociedad Extremeña de Historia, pp. 177-190.

VIÑA BRITO, A. (2013). «Ordenanzas sobre el azúcar de caña en el siglo XVI: un análisis comparativo». Historia. Instituciones. Documentos, núm. 40, pp. 397-425.

VIÑA BRITO, A. (2014). «El azúcar como eje vertebrador de la sociedad canaria en el siglo XVI». En VIÑA BRITO, A. (ed.), Azúcar y mecenazgo en Gran Canaria. El oro de las Islas, siglos $X V$-XVI. Las Palmas de Gran Canaria: Cabildo de Gran Canaria, pp. 15-50.

VIÑA BRITO, A. (2015). «Espacios atlánticos del azúcar: precedentes canarios». Ciencia Nicolaita, núm. 64, pp. 76-99. Recuperado de

https://www.cic.cn.umich.mx/cn/article/view/250

VIÑA BRITO, A. (2019). «Canarias, sociedad de frontera». En GARCÍA FERNÁNDEZ, M.; GALÁN, A. y PEINADO, R. (eds.), Las fronteras en la Edad Media hispánica, siglos XIIIXVI. Granada-Sevilla: Universidad de Granada-Universidad de Sevilla, pp. 441-460.

VIÑA BRITO, A.; CORRALES, C. y CORBELLA, D. (2014 y 2016). Islas y Voces del Azúcar I (Tenerife, La Gomera y La Palma) y II (Gran Canaria). Santa Cruz de Tenerife: Archivos Históricos Provinciales de S/C de Tenerife y de Las Palmas de Gran Canaria.

WAGNER, K. (1973). «La Inquisición en Sevilla. Notas al margen de las actas notariales del Archivo de Protocolos de Sevilla referentes a los autos de fe celebrados en dicha ciudad». En Homenaje al profesor Carriazo. Sevilla: , tomo 3, pp. 441-460.

YANISHEV NESTEROVA, I. (2019). Canarias en las relaciones hispano-soviéticas 1965 1991. Santa Cruz de Tenerife: Ediciones Idea. 